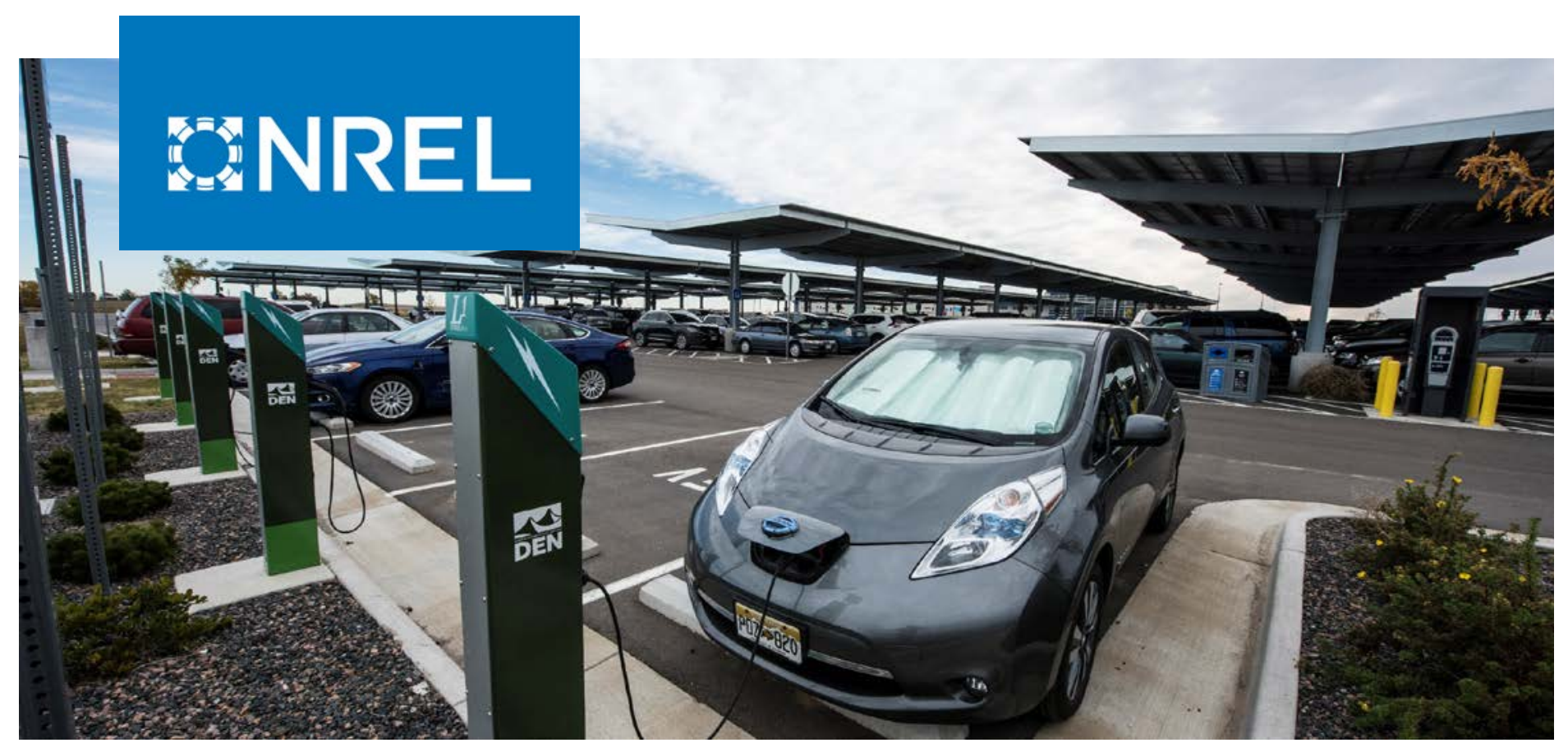

\title{
Electric Vehicle Charging Infrastructure Trends from the Alternative Fueling Station Locator: Fourth Quarter 2020
}

Abby Brown, ${ }^{1}$ Stephen Lommele, ${ }^{1}$ Alexis Schayowitz, ${ }^{2}$ and Emily Klotz ${ }^{2}$

1 National Renewable Energy Laboratory 2 ICF

NREL is a national laboratory of the U.S. Department of Energy Office of Energy Efficiency \& Renewable Energy

Operated by the Alliance for Sustainable Energy, LLC

This report is available at no cost from the National Renewable Energy Laboratory (NREL) at www.nrel.gov/publications.
Technical Report

NREL/TP-5400-80120

June 2021 


\title{
GNREL
}

\section{Electric Vehicle Charging Infrastructure Trends from the Alternative Fueling Station Locator: Fourth Quarter 2020}

\author{
Abby Brown, ${ }^{1}$ Stephen Lommele, ${ }^{1}$ Alexis Schayowitz, ${ }^{2}$ \\ and Emily Klotz ${ }^{2}$
}

1 National Renewable Energy Laboratory

2 ICF

\section{Suggested Citation}

Brown, Abby, Stephen Lommele, Alexis Schayowitz, and Emily Klotz. 2021. Electric Vehicle Charging Infrastructure Trends from the Alternative Fueling Station Locator: Fourth Quarter 2020. Golden, CO: National Renewable Energy Laboratory. NREL/TP5400-80120. https://www.nrel.gov/docs/fy21osti/80120.pdf.

NREL is a national laboratory of the U.S. Department of Energy Office of Energy Efficiency \& Renewable Energy Operated by the Alliance for Sustainable Energy, LLC

This report is available at no cost from the National Renewable Energy Laboratory (NREL) at www.nrel.gov/publications.

Contract No. DE-AC36-08GO28308
Technical Report NREL/TP-5400-80120 June 2021

National Renewable Energy Laboratory 15013 Denver West Parkway Golden, CO 80401 303-275-3000 • www.nrel.gov 


\section{NOTICE}

This work was authored [in part] by the National Renewable Energy Laboratory, operated by Alliance for Sustainable Energy, LLC, for the U.S. Department of Energy (DOE) under Contract No. DE-AC3608GO28308. Funding provided by the U.S. Department of Energy Office of Energy Efficiency and Renewable Energy's Vehicle Technologies Office. The views expressed herein do not necessarily represent the views of the DOE or the U.S. Government.

This report is available at no cost from the National

Renewable Energy Laboratory (NREL) at

www.nrel.gov/publications.

U.S. Department of Energy (DOE) reports produced

after 1991 and a growing number of pre-1991

documents are available

free via www.OSTI.gov.

Cover Photo by Dennis Schroeder: NREL 48761.

NREL prints on paper that contains recycled content. 


\section{Acknowledgments}

Funding for this report came from the U.S. Department of Energy Office of Energy Efficiency and Renewable Energy's Vehicle Technologies Office. The Station Locator team collected the data used to generate this report with the help of electric vehicle (EV) charging networks, charging infrastructure providers and developers, Clean Cities Coalition Network coordinators, industry associations, original equipment manufacturers, state and local government agencies, utilities, fleets, EV drivers, and other industry stakeholders. The authors relied on the valuable contributions of reviewers, including Eric Wood, National Renewable Energy Laboratory; Kevin Wood, Center for Sustainable Energy/San Diego Clean Cities; Joseph Cryer, Southern California Association of Governments/Southern California Clean Cities; and Dan Bowerson, Alliance for Automotive Innovation. 


\section{List of Acronyms}

\begin{tabular}{|c|c|}
\hline AFDC & Alternative Fuels Data Center \\
\hline AMPUP & AmpUp network \\
\hline API & application program interface \\
\hline $\mathrm{BN}$ & Blink network \\
\hline $\mathrm{CCS}$ & Combined Charging System \\
\hline CHARGELAB & ChargeLab network \\
\hline $\mathrm{CPN}$ & ChargePoint network \\
\hline $\mathrm{DC}$ & direct-current \\
\hline DOE & U.S. Department of Energy \\
\hline E85 & $\begin{array}{l}\text { ethanol blend containing } 51 \% \text { to } 83 \% \text { ethanol, depending on geography } \\
\text { and season }\end{array}$ \\
\hline EA & Electrify America network \\
\hline EV & all-electric vehicle \\
\hline $\mathrm{EVC}$ & EV Connect network \\
\hline EVCS & EV Charging Solutions network \\
\hline EVGATEWAY & evGateway network \\
\hline EVN & EVgo network \\
\hline EVSE & electric vehicle supply equipment \\
\hline EVSP & electric vehicle service provider \\
\hline FCN & Francis Energy network \\
\hline FLO & FLO network \\
\hline FPLEV & FPL EVolution \\
\hline GE & General Electric \\
\hline GRN & Greenlots network \\
\hline L1 & Level 1 charger \\
\hline L2 & Level 2 charger \\
\hline MUD & multi-unit dwelling, also referred to as multi-family building \\
\hline NON & non-networked \\
\hline NREL & National Renewable Energy Laboratory \\
\hline $\mathrm{OC}$ & OpConnect network \\
\hline OCPI & Open Charge Point Interface \\
\hline OEM & original equipment manufacturer \\
\hline PEV & plug-in electric vehicle \\
\hline POWERFLEX & PowerFlex network \\
\hline Q1 & quarter 1 , or first quarter of the calendar year \\
\hline Q2 & quarter 2 , or second quarter of the calendar year \\
\hline Q3 & quarter 3 , or third quarter of the calendar year \\
\hline Q4 & quarter 4 , or fourth quarter of the calendar year \\
\hline $\mathrm{SCN}$ & SemaConnect network \\
\hline TESLA & Tesla Supercharger network \\
\hline TESLAD & Tesla Destination network \\
\hline VLTA & Volta network \\
\hline WEB & Webasto network \\
\hline ZETA & Zero Emission Transportation Association \\
\hline
\end{tabular}

iv 


\section{Executive Summary}

The U.S. Department of Energy's (DOE's) Alternative Fueling Station Locator contains information on public and private non-residential alternative fueling stations in the United States and Canada and currently tracks ethanol (E85), biodiesel, compressed natural gas, electric vehicle (EV) charging, hydrogen, liquefied natural gas, and propane stations. Of these fuels, EV charging continues to experience rapidly changing technology and growing infrastructure. This report provides a snapshot of the state of EV charging infrastructure in the United States in the fourth calendar quarter of 2020 (Q4). Using data from the Station Locator, this report breaks down the growth of public and private charging infrastructure by charging level, network, and location. Additionally, this report measures the current state of charging infrastructure compared with the projected amount needed to meet charging demand by 2030 . This information is intended to help transportation planners, policymakers, researchers, infrastructure developers, and others understand the rapidly changing landscape for EV charging. This is the fourth report in a series. Previous reports for the first (Q1), second (Q2), and third (Q3) calendar quarters of 2020 can be found in the Alternative Fuels Data Center (AFDC) and National Renewable Energy Laboratory (NREL) publication databases.

In Q4, all categories of electric vehicle supply equipment (EVSE) grew, except for public and private Level 1 EVSE, which decreased by $1.7 \%$ and $0.3 \%$, respectively, and private Level 2 EVSE, which decreased by $1.0 \%$. Overall, there was a $7.7 \%$ increase in the number of EVSE in the Station Locator. The majority of EVSE in the Station Locator are Level 2, though directcurrent (DC) fast charger EVSE grew by the largest percentage in Q4. California had the largest increase in public charging infrastructure in Q4 and continues to lead the country in the number of available public EVSE.

NREL's 2017 National Plug-In Electric Vehicle Infrastructure Analysis estimated how much public and workplace charging infrastructure would be required in the United States to meet charging needs for a central scenario in which 15 million light-duty plug-in electric vehicles (PEVs) are on the road by 2030 (601,000 Level 2 and 27,500 DC fast EVSE) (Wood et al. 2017). Based on this analysis, about $63.5 \%$ and $14.3 \%$ of the necessary DC fast and Level 2 EVSE, respectively, have been installed as of Q4. However, in Q4, the number of DC fast EVSE and Level 2 EVSE per 1,000 PEVs currently on the road was 10.7 and 52.5 respectively, compared with NREL's projected need of 1.8 and 40.1, respectively. This indicates that infrastructure development is keeping up with, and even surpassing, forecasted needs. It is important to note, however, that the majority $(54.2 \%)$ of public DC fast EVSE in the Station Locator are on the Tesla network and are therefore only readily accessible to Tesla drivers. 


\section{Table of Contents}

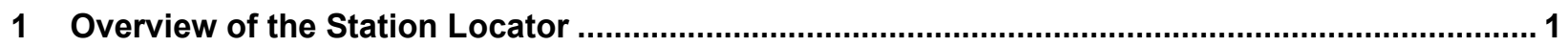

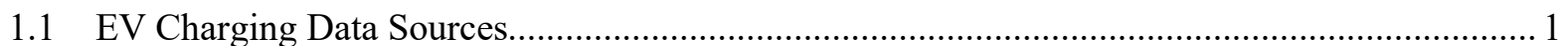

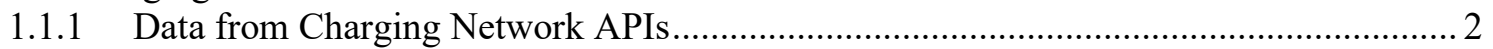

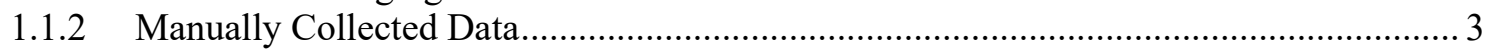

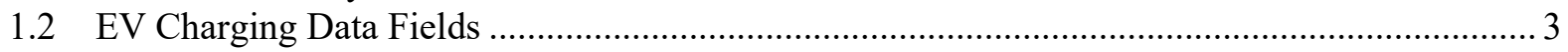

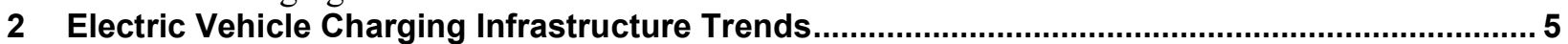

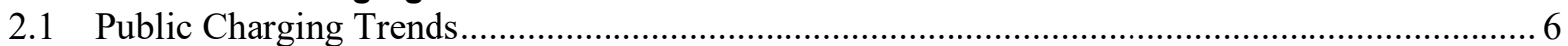

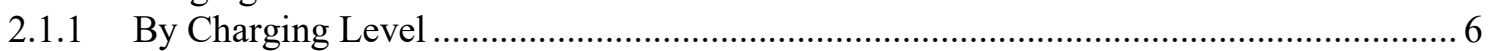

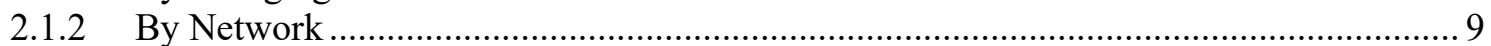

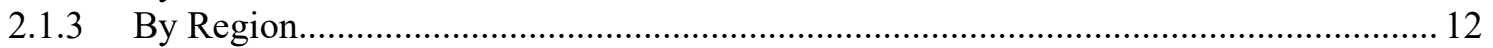

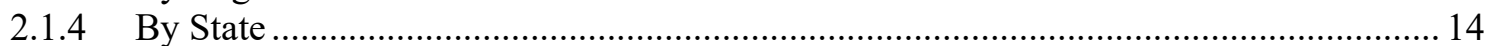

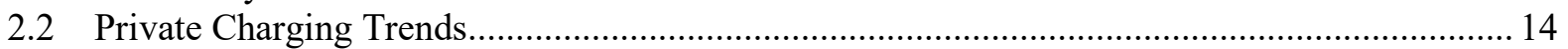

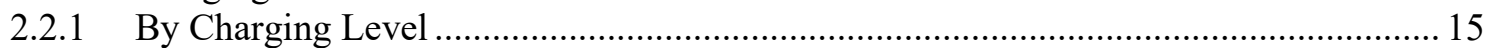

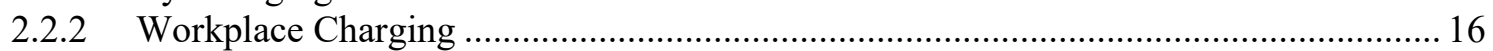

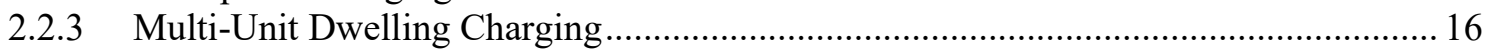

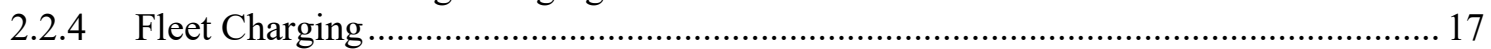

3 Projecting Future Charging Infrastructure Needs.............................................................. 17

4 Developments That Could Impact Future Quarters .............................................................. 20

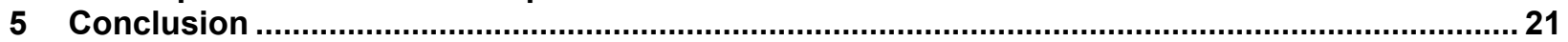

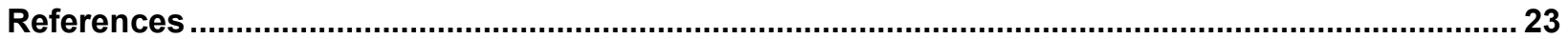




\section{List of Figures}

Figure 1. Non-networked vs. networked EV charging stations ........................................... 2

Figure 2. Timeline of API integrations in the Station Locator .......................................... 2

Figure 3. EV charging infrastructure hierarchy as defined in OCPI ................................... 4

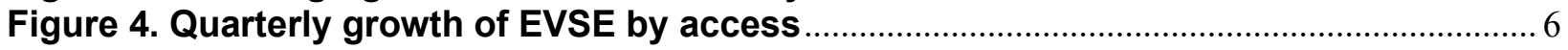

Figure 5. Quarterly growth of public EVSE by charging level......................................... 7

Figure 6. Quarterly growth of public DC fast EVSE by power output ................................. 8

Figure 7. Quarterly Growth of Public DC Fast Connectors by Type. ................................... 9

Figure 8. Quarterly growth of networks in the Station Locator .............................................9

Figure 9. Breakdown of public EVSE by network and charging level in Q4 ..................... 10

Figure 10. Breakdown of public DC fast EVSE by network in Q4 ..................................... 10

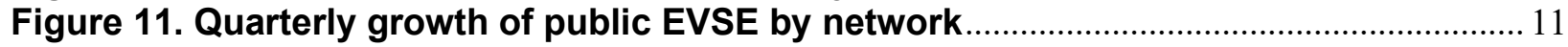

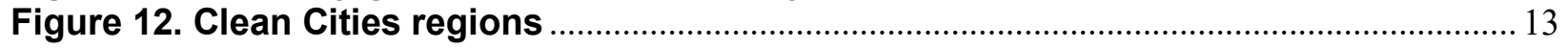

Figure 13. Quarterly growth of public EVSE by Clean Cities region ................................. 13

Figure 14. Quarterly growth of private EVSE by charging level ........................................ 15

Figure 15. Quarterly growth of private workplace EVSE by charging level ....................... 16

Figure 16. Quarterly growth of private MUD EVSE by charging level............................... 17

Figure 17. Current availability and projected 2030 need of public and workplace charging in the United States.

Figure 18. Quarterly availability and projected 2030 need of public and workplace EVSE per 1,000 EVs in the United States

\section{List of Tables}

Table 1. Quarterly Growth of Public EVSE by Network ...................................................... 12

Table 2. States with the Highest Rate of EVSE per 100,000 People .................................. 14

Table 3. States with the Largest Growth of EVSE per 100,000 People ............................... 14 


\section{Overview of the Station Locator}

The U.S. Department of Energy's (DOE) Alternative Fuels Data Center (AFDC) launched in 1991 in response to the Alternative Motor Fuels Act of 1988 and the Clean Air Act Amendments of 1990 (Alternative Fuels Data Center 2020a). Originally, it served as a hard copy resource for alternative fuel performance data and eventually became an internet resource in 1995 . Since then, the AFDC has evolved dramatically into a robust online resource that provides a broad range of information on alternative fuels and advanced transportation technologies, including fueling and charging station data. In 2017, the National Renewable Energy Laboratory (NREL) partnered with National Resources Canada to expand the data set to include the location of those same alternative fuel stations across Canada as the Electric Charging and Alternative Fueling Stations Locator, or Localisateur de stations de recharge et de stations de ravitaillement en carburants de remplacement (Levene et al. 2019). The Station Locator database now includes information on public and private nonresidential alternative fueling stations in the United States and Canada and currently tracks ethanol (E85), biodiesel, compressed natural gas, electric vehicle (EV) charging, hydrogen, liquefied natural gas, and propane stations.

Although historical data for all fuel types in the Station Locator are available, it is especially important to take an in-depth look at EV charging due to rapidly changing technology and growing infrastructure. This trend is likely to continue as original equipment manufacturers (OEMs) offer more EV models, more utilities begin offering incentives for EVs and infrastructure, and states and municipalities set electrification goals and mandates. Using Station Locator data, this paper explores the growth of both public and private EV charging infrastructure in the United States for the fourth calendar quarter of 2020 (Q4). This is the fourth report in a series. Previous reports for the first (Q1), second (Q2), and third (Q3) calendar quarters of 2020 can be found in the AFDC and NREL publication databases.

\subsection{EV Charging Data Sources}

NREL and its data collection contractor and collaborator, ICF, use a variety of methods to gather and verify EV charging data in the Station Locator. Electric vehicle service providers (EVSPs), responsible for managing a network of EV charging stations (Figure 1), share data directly with the Station Locator team and are the largest data source for EV charging in the Station Locator. In addition, data are collected through industry outreach, Clean Cities coordinators, and other manual methods. 


\section{Non-Networked Stations}

Non-networked EV charging stations are not connected to the internet and provide basic charging functionality without advanced communications capabilities. Because of this, non-networked charging is generally free or offered as an amenity for those who pay for parking or to access a business.

\section{Networked Stations}

Networked EV charging stations are connected to the internet via a cable or wireless technology and can communicate with the back-end computer system of an EVSP. Being connected to a network lets station owners or site hosts manage who can access stations and control how much it costs drivers to charge their vehicle. An EVSP typically manages a group of networked EVSE, otherwise known as a network, and may use its communication capabilities to communicate directly with drivers, other EVSPs, or utilities; monitor and share real-time station status; broadcast location information; collect and store usage data; control access; or facilitate payment. For a group of networked EVSE to be considered a network, it cannot be considered part of another network and it must have a dedicated platform that allows users to locate EV charging stations, as well as initiate and pay for charging events.

\section{Figure 1. Non-networked vs. networked EV charging stations}

\subsubsection{Data from Charging Network APIs}

Prior to 2014, NREL manually collected all EV charging data, including EV charging stations managed by EVSPs. In 2014, to keep up with the rapid growth of charging infrastructure, NREL began incorporating daily updates on networked charging station data directly from EVSPs when available. NREL does this by accessing the network's application program interface (API) and importing each network's API data into the database. Using APIs ensures the efficiency, accuracy, and completeness of the data are maintained.

Figure 2 shows a timeline of the integration of the network APIs into the Station Locator data management process. Open Charge Point Interface (OCPI)-based APIs that have been integrated into the Station Locator are also shown in Figure 2 See Section 1.2 for more information on OCPI.

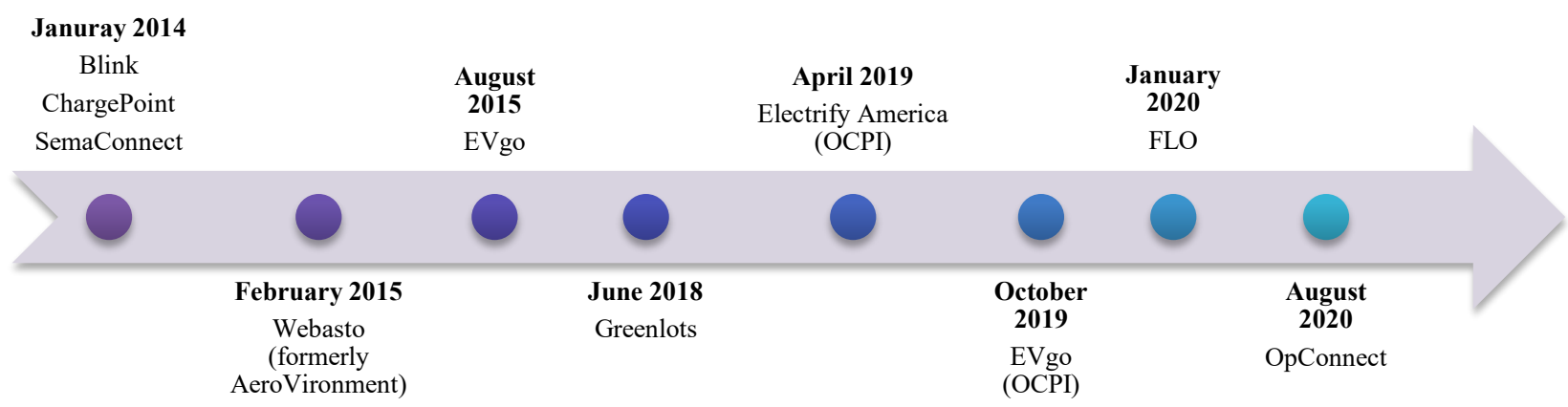

Figure 2. Timeline of API integrations in the Station Locator

As of December 2020, there were 31,738 public and private charging stations in the database, which are available on the Station Locator or accessible via API or data download (Alternative 
Fuels Data Center 2020b). Of those, approximately 55\% are automatically updated daily via EVSP-provided APIs, whereas the rest are managed and updated manually.

The Station Locator team is working with additional EVSPs to access and integrate existing APIs or provide them with best practices on developing an API if they have not yet automated their data sharing. This will help ensure station data are as current and accurate as possible, while also increasing the efficiency of the EV charging data update process.

\subsubsection{Manually Collected Data}

For non-networked (i.e., not connected to the internet) stations, data sources include trade media, Clean Cities coordinators, a "Submit New Station" form on the Station Locator website, EV charging station manufacturers, electric utilities, OEMs, state and municipal governments, private companies, and others. The Station Locator team regularly monitors news outlets for press releases on new EV charging station openings and seeks out more information as appropriate to confirm and add the EV charging data to the Station Locator.

The Station Locator team also receives semiregular data in the form of spreadsheets from EVSPs that do not have an API available. These EVSPs include EV Connect, Tesla, and Volta. In Q4, the team received updates from the EV Connect and Tesla Destination networks. Additionally, the team receives regular updates from Chargeway that include stations on all networks. The team is greatly appreciative of their continued collaboration and willingness to share regular data updates.

Finally, Clean Cities coalitions (see Section 2.1.3) proactively provide information on station updates and additions throughout the year. Coalitions also serve as a valuable on-the-ground resource for stations that ICF is not able to confirm through normal station confirmation processes. Unconfirmed stations are sent to coalitions throughout the year for confirmation; if the coalition is not able to provide any additional information, the station is subsequently removed from the Station Locator.

It is important to state these reports reflect a snapshot of the number of available EVSE in the Station Locator at the end of each quarter. Therefore, notable changes may be attributed to the manual data collection process as new manually added EVSE is counted in the quarter in which it is added to the Station Locator as opposed to when the infrastructure was installed. Additionally, stations that are temporarily out of service are not included in these reports.

\subsection{EV Charging Data Fields}

Current charging infrastructure in the Station Locator generally falls into the following categories:

- Public: A broad category that includes EV charging located in publicly accessible areas or along highway corridors

- Workplace: EV charging intended to provide charging to employees during the workday

- Commercial/Fleet: EV charging intended to provide charging for electric fleet vehicles, including municipal/private fleets, car sharing, and transportation network companies. 
Note that although fleet data exist in the Station Locator, stations solely for fleet use are not yet designated as such in the Station Locator. The Station Locator team has recently added this level of tracking and will therefore be able to designate stations as such moving forward. See Section 3.4 for more details.

Additionally, the Station Locator does not maintain data on single-family residential charging and has minimal, yet expanding, data on charging at multi-unit dwellings (MUDs, also referred to as multifamily buildings). See Section 3.3 for additional details.

In 2019, the Station Locator team began transitioning its counting logic to align with the hierarchy defined in the OCPI protocol: locations, EVSE, and connectors (EVRoaming Foundation 2019), as shown in Figure 3 and described in this section. With this transition, the Station Locator is now counting the number of EVSE at a station location, rather than the number of connectors previously counted.

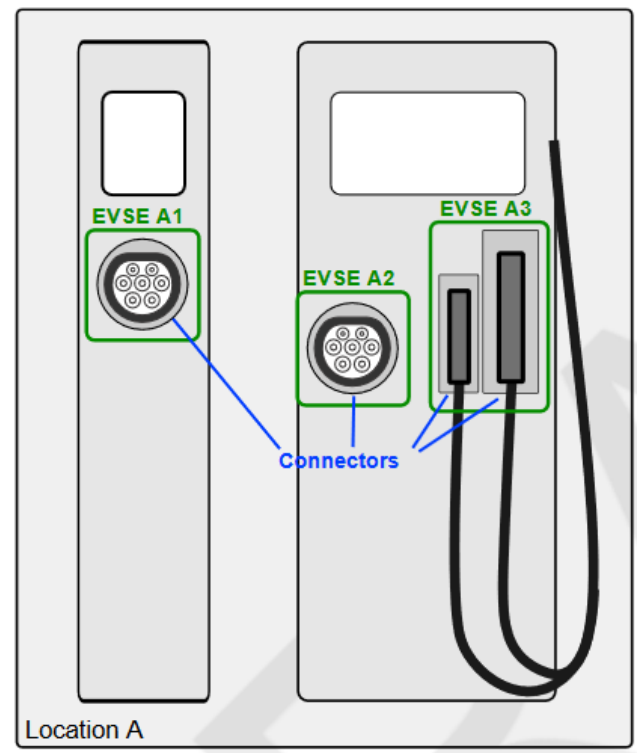

Figure 3. EV charging infrastructure hierarchy as defined in OCPI

Source: EVRoaming Foundation (2019)

The following fuel-specific fields are tracked in the Station Locator for EV charging stations (Alternative Fuels Data Center 2020c):

- EV charger information:

- EV charging station: one or more EVSE located at the same address

- EVSE count: number of outlets or ports (i.e., number of vehicles that can simultaneously charge at a charging station)

- Charger type

- Level 1 (L1): $120 \mathrm{~V} ; 1$ hour of charging $=2-5$ miles of range

- Level 2 (L2): $240 \mathrm{~V} ; 1$ hour of charging $=10-20$ miles of range 
- Direct-current (DC) fast: 480+ V; 20 minutes of charging $=60-80$ miles of range

- Connectors (number and type)

- NEMA: for Level 1 chargers

- J1772: for Level 1 and Level 2 chargers

- Combined Charging System (CCS): for DC fast chargers

- CHAdeMO: for DC fast chargers

- Tesla: for all charging levels for Tesla vehicles

○ Network

○ Manufacturer

○ Power output $(\mathrm{kW})$

- Open date

- Workplace

- Pricing

- On-site renewable electricity source.

These fields and the associated definitions are used in the analysis that follows.

\section{Electric Vehicle Charging Infrastructure Trends}

The purpose of this report is to identify EV charging infrastructure trends for Q4 of 2020. However, as previously mentioned, the Station Locator has been collecting data on alternative fueling stations since the 1990s, and therefore has historical EV charging station data for several years that can serve as a baseline for more analysis. See the first report in this series for the growth of EVSE and EV charging stations in the Station Locator over the last 10 years (Brown et al. 2020a).

In Q4, the number of EVSE in the Station Locator grew by 7.7\%, or 7,960 EVSE. Public EVSE grew by $9.2 \%$ and account for the majority of EVSE in the Station Locator (Figure 4). Private EVSE decreased by $0.9 \%$ (Figure 4). This decrease is discussed in more detail in Section 3.1. 


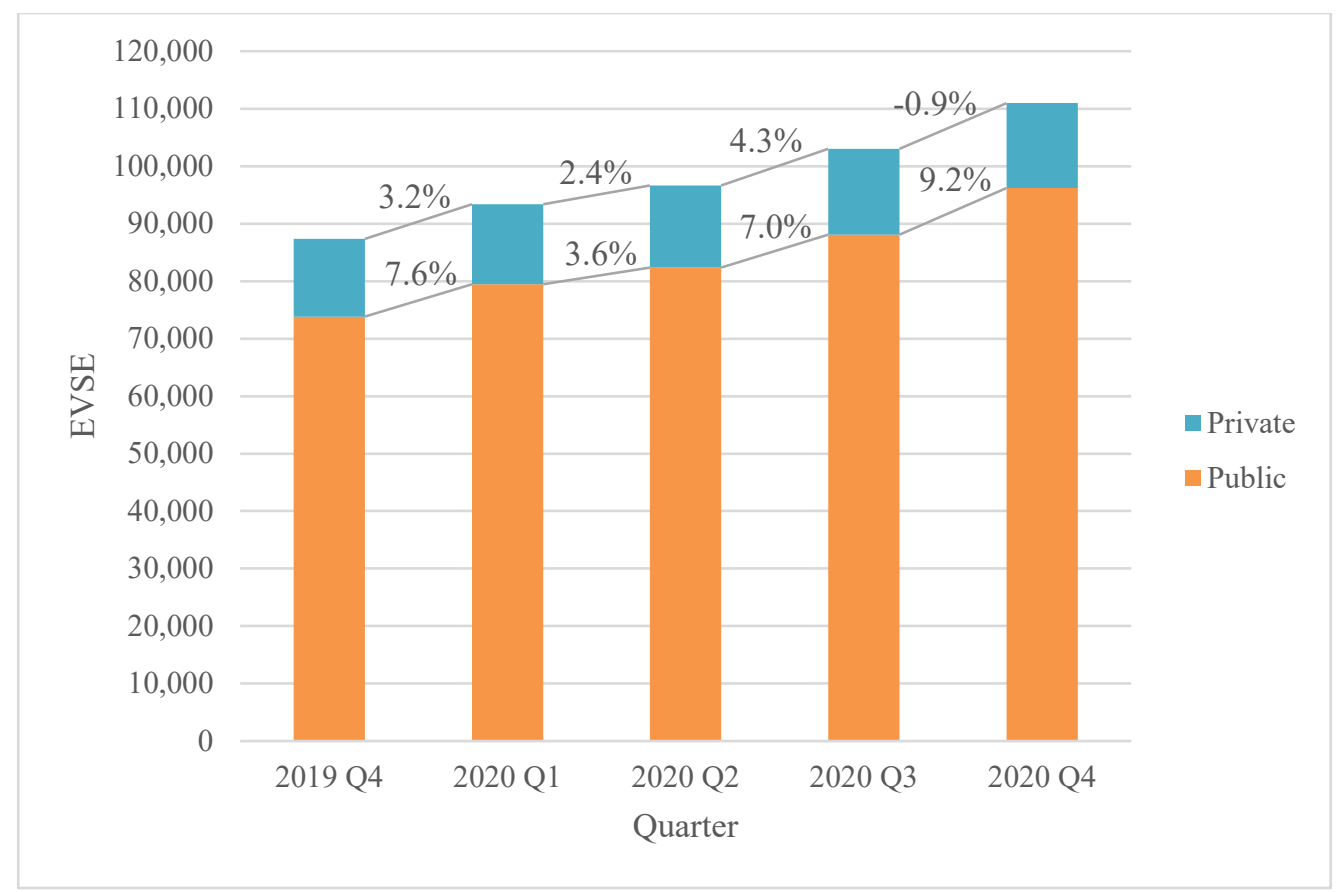

Figure 4. Quarterly growth of EVSE by access

The following sections break down the growth of public and private EVSE further to highlight what types of EV infrastructure grew in Q4 and where EV infrastructure has grown geographically. Because the number of EVSE represents the number of vehicles that can charge simultaneously at an EV charging station, the remainder of this report will focus on EVSE growth.

\subsection{Public Charging Trends}

As previously mentioned, public EV charging refers to EV charging stations that are available to all EV drivers and located in publicly accessible locations, such as commercial locations or along highway corridors. In Q4, the number of public EVSE in the Station Locator increased by 8,097, bringing the total number of public EVSE in the Station Locator to 96,190 and representing a 9.2\% increase since Q3. The following sections break down the growth of public EVSE by charging level, network, region, and state.

\subsubsection{By Charging Level}

As shown in Figure 5, the majority of public EVSE in the Station Locator are Level 2, followed by DC fast and Level 1. In Q4, DC fast EVSE increased by the greatest percentage (10.8\%), whereas Level 1 EVSE decreased by 1.7\% (Figure 5). The decrease in public Level 1 EVSE can be primarily attributed to closures of non-networked stations that were installed in 2015 or earlier. 


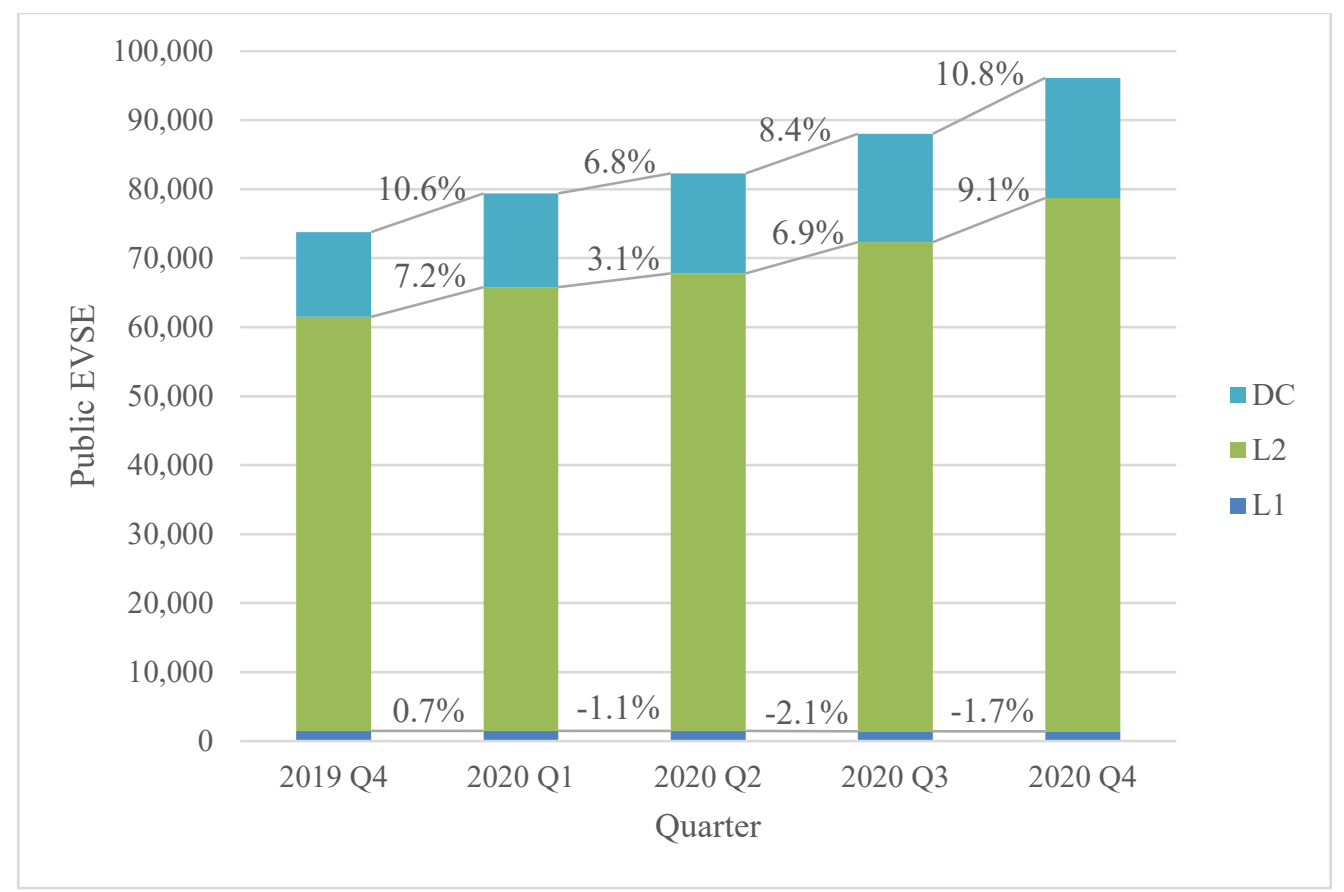

Figure 5. Quarterly growth of public EVSE by charging level

When compared with Level 1 and Level 2 chargers, DC fast chargers have the highest power output and therefore provide the most charge in the least amount of time. DC fast chargers have a standard power output of $50 \mathrm{~kW}$, though DC fast chargers with higher levels of power output are available. Extreme fast charging infrastructure, which has a power output of $350 \mathrm{~kW}$ or more, was introduced in 2018. However, as shown in Figure 6, the majority of DC fast EVSE in the Station Locator still currently have the standard power output of $50 \mathrm{~kW}$ or less.

It is important to point out that of the 17,430 public DC fast EVSE in the Station Locator, power output data are currently only available for $37.3 \%$; Figure 6 is therefore based on power output data for 6,498 DC fast EVSE. NREL is in the process of integrating updated OCPI-based APIs to streamline the collection of power output data and create a more complete data set. Additionally, if a DC fast EVSE has two connectors with different power outputs, only the maximum power output is counted in Figure 6.

As shown in Figure 6, the number of EVSE with a power output between $51 \mathrm{~kW}$ and $299 \mathrm{~kW}$ grew by the largest percentage in Q4 (31.6\%), and the number of EVSE with a power output greater than $299 \mathrm{~kW}$ grew by $23.1 \%$. As previously discussed, the number of public DC fast EVSE grew by more than $10 \%$ in Q4, which contributed to these large increases. More specifically, the growth in EVSE with a power output between $51 \mathrm{~kW}$ and $299 \mathrm{~kW}$ can be attributed to the Electrify America, EVgo, ChargePoint, and Tesla Supercharger networks, whereas the growth in EVSE with a power output greater than $299 \mathrm{~kW}$ can be attributed entirely to Electrify America. See Section 2.1.2 for a discussion on Electrify America's Q4 growth.

Additionally, Electrify America and EVgo temporarily adjust the power output of their DC fast chargers down to $50 \mathrm{~kW}$ while maintenance or upgrades are being performed. This contributed to the decreases seen in Q3 as well as the increases seen in Q4, as the chargers that had been 
adjusted down to $50 \mathrm{~kW}$ were adjusted back to their original, higher power output (Figure 6). The Station Locator team expects to continue to see fluctuations in DC fast EVSE power output data as a result of these adjustments.

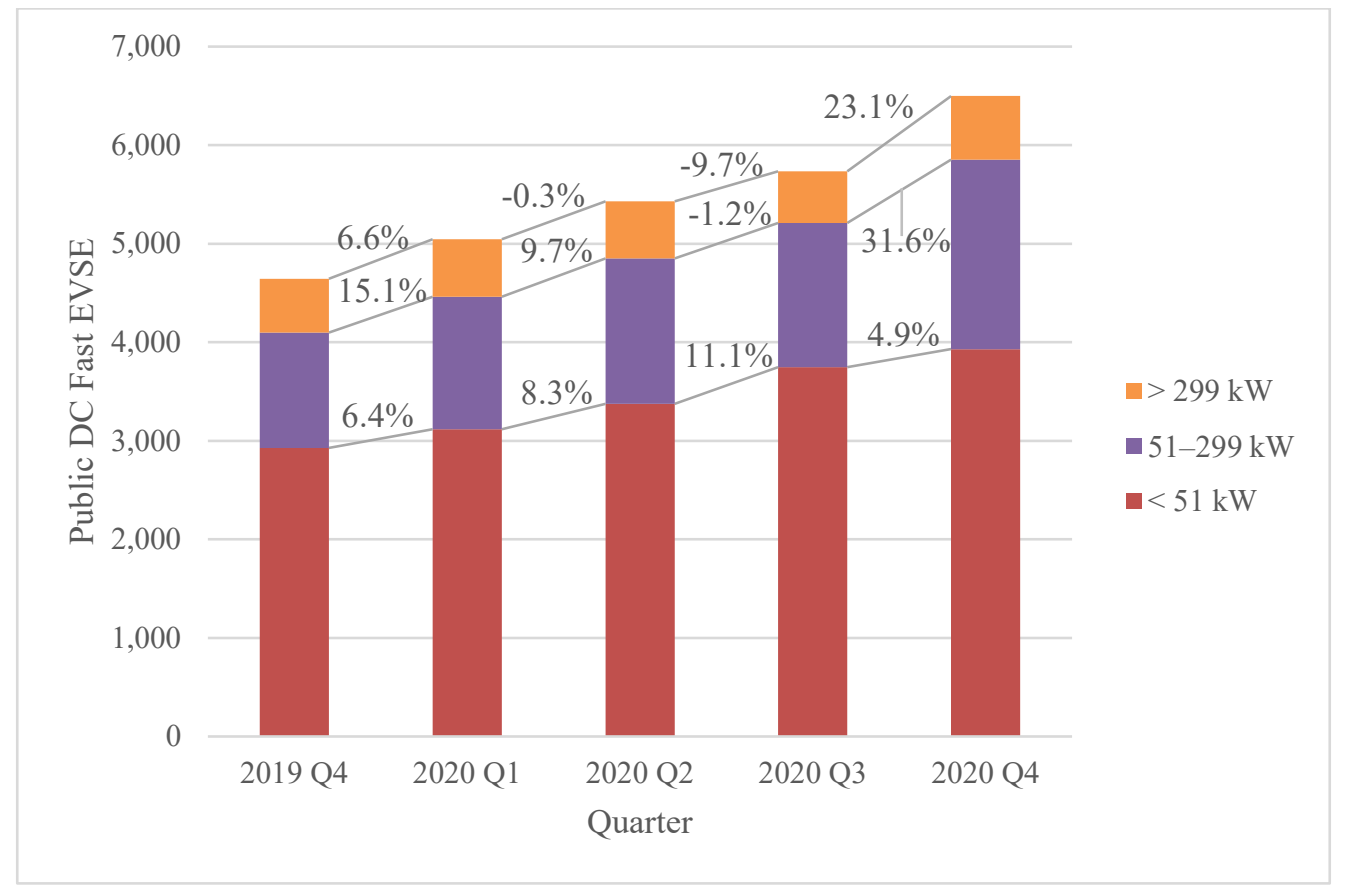

Figure 6. Quarterly growth of public DC fast EVSE by power output

There are currently three types of connectors that are available for DC fast chargers: CHAdeMO, CCS, and Tesla. Of the 19,719 DC fast connectors in the Station Locator as of Q4, Tesla connectors made up the largest proportion of connectors, though CCS connectors grew by the largest proportion (12.4\%) (Figure 7). 


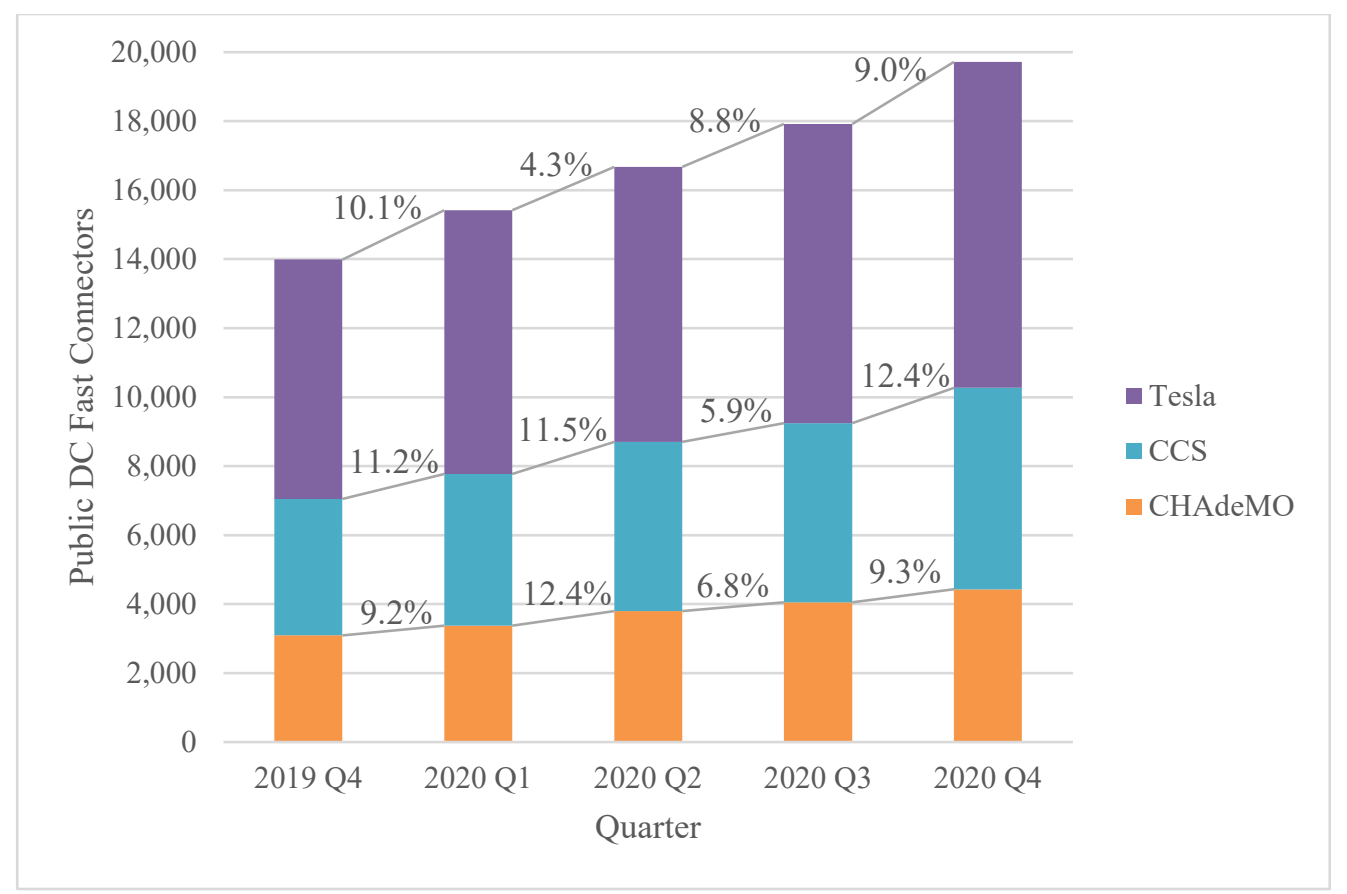

Figure 7. Quarterly Growth of Public DC Fast Connectors by Type.

\subsubsection{By Network}

As discussed in Section 1.1, the Station Locator team works with most major EVSPs to collect EV charging infrastructure data for the Station Locator. Currently, the Station Locator includes stations on the networks listed in this section. The AmpUp, ChargeLab, and EV Charging Solutions networks were new to the Station Locator as of Q4, bringing the total number of networks in the Station Locator to 21 (Figure 8). In addition, the Station Locator contains nonnetworked (NON) station data, which include stations that were previously networked.

- $A m p U p($ AMPUP)

- $\operatorname{Blink}(\mathrm{BN})$

- ChargeLab (CHARGELAB)

- ChargePoint (CPN)

- Electrify America (EA)

- EV Connect (EVC)

- EV Charging Solutions (EVCS)

- evGateway (EVGATEWAY)

- EVgo (EVN)

- Francis Energy (FCN)
- FLO (FLO)

- FPL EVolution (FPLEV)

- Greenlots (GRN)

- OpConnect (OC)

- Powerflex (POWERFLEX)

- SemaConnect (SCN)

- Tesla Supercharger (TESLA)

- Tesla Destination (TESLAD)

- Volta (VLTA)

- Webasto (WEB) 


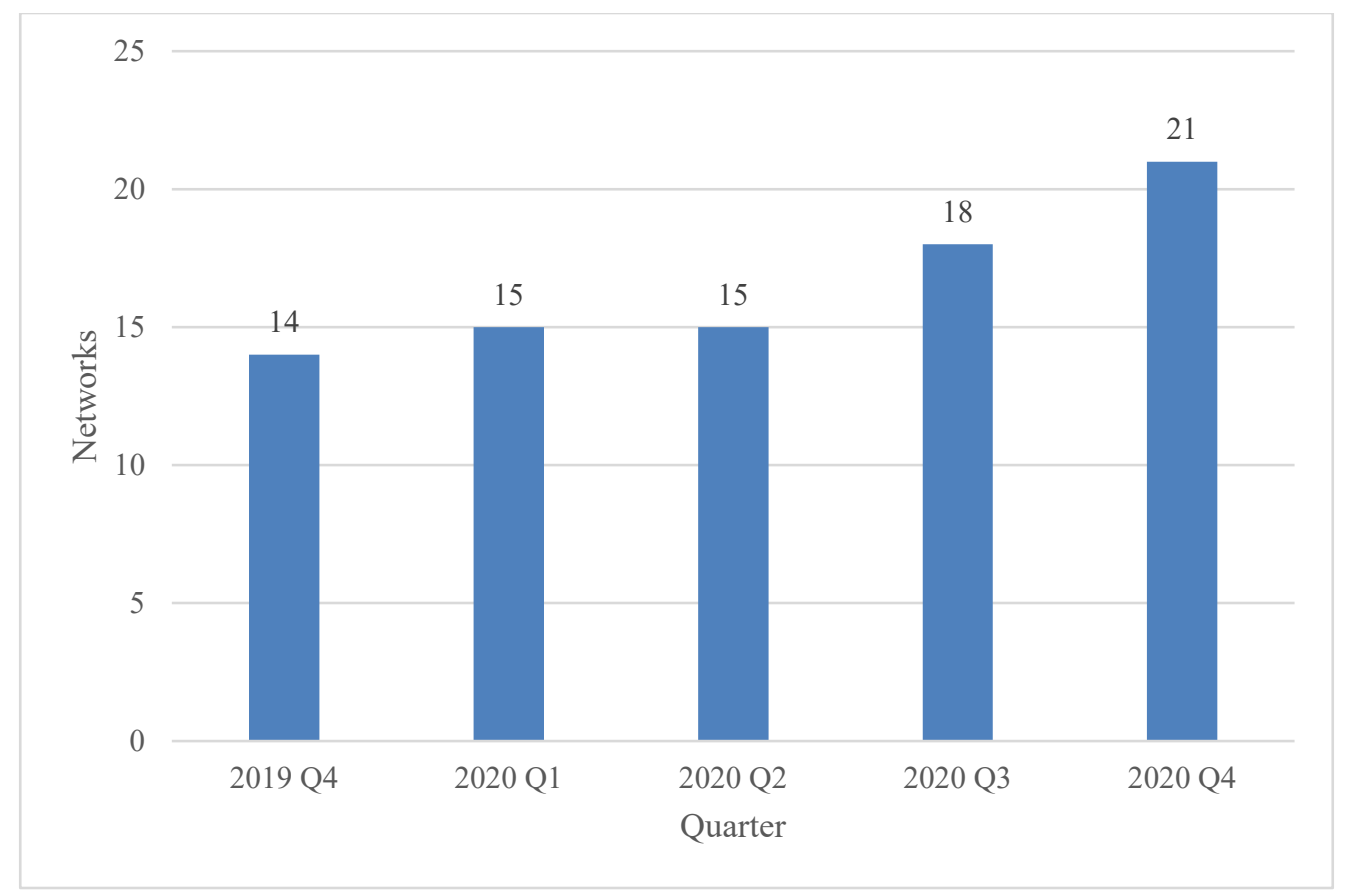

Figure 8. Quarterly growth of networks in the Station Locator

As of the end of Q4, the ChargePoint network accounted for the largest number of public EVSE $(41.8 \%)$ in the Station Locator, and Level 2 chargers constituted the majority of ChargePoint's network (Figure 9). This holds true for many of the networks in the Station Locator, except for the Electrify America, EVgo, Francis, FPL EVolution, and Tesla Supercharger networks. These networks are predominately, if not completely, made up of DC fast chargers. Of the networks with DC fast chargers, Tesla Supercharger has the largest share of public DC fast EVSE (54.2\%), followed by Electrify America (13.5\%), and ChargePoint (12.3\%) (Figure 10). 


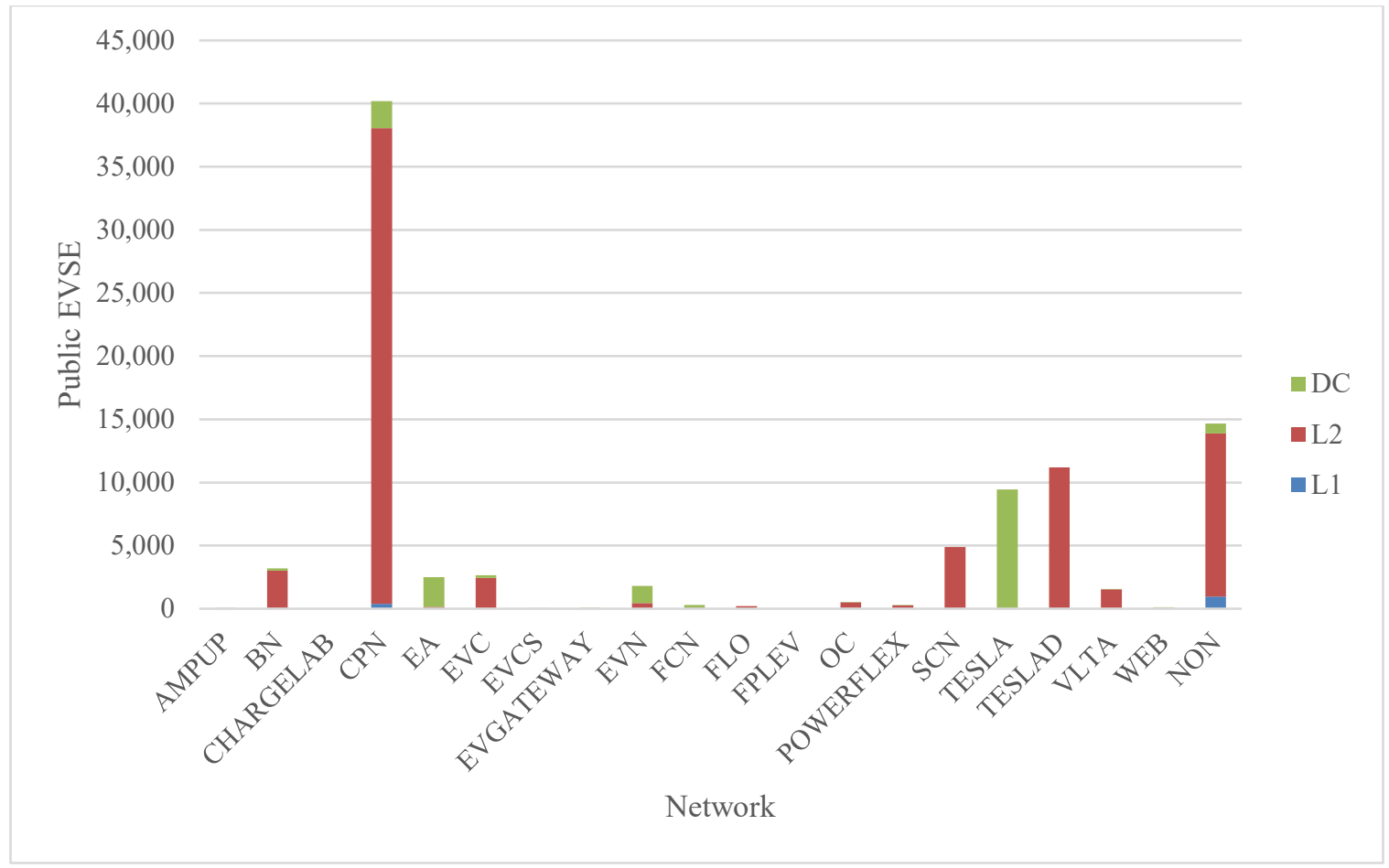

Figure 9. Breakdown of public EVSE by network and charging level in Q4

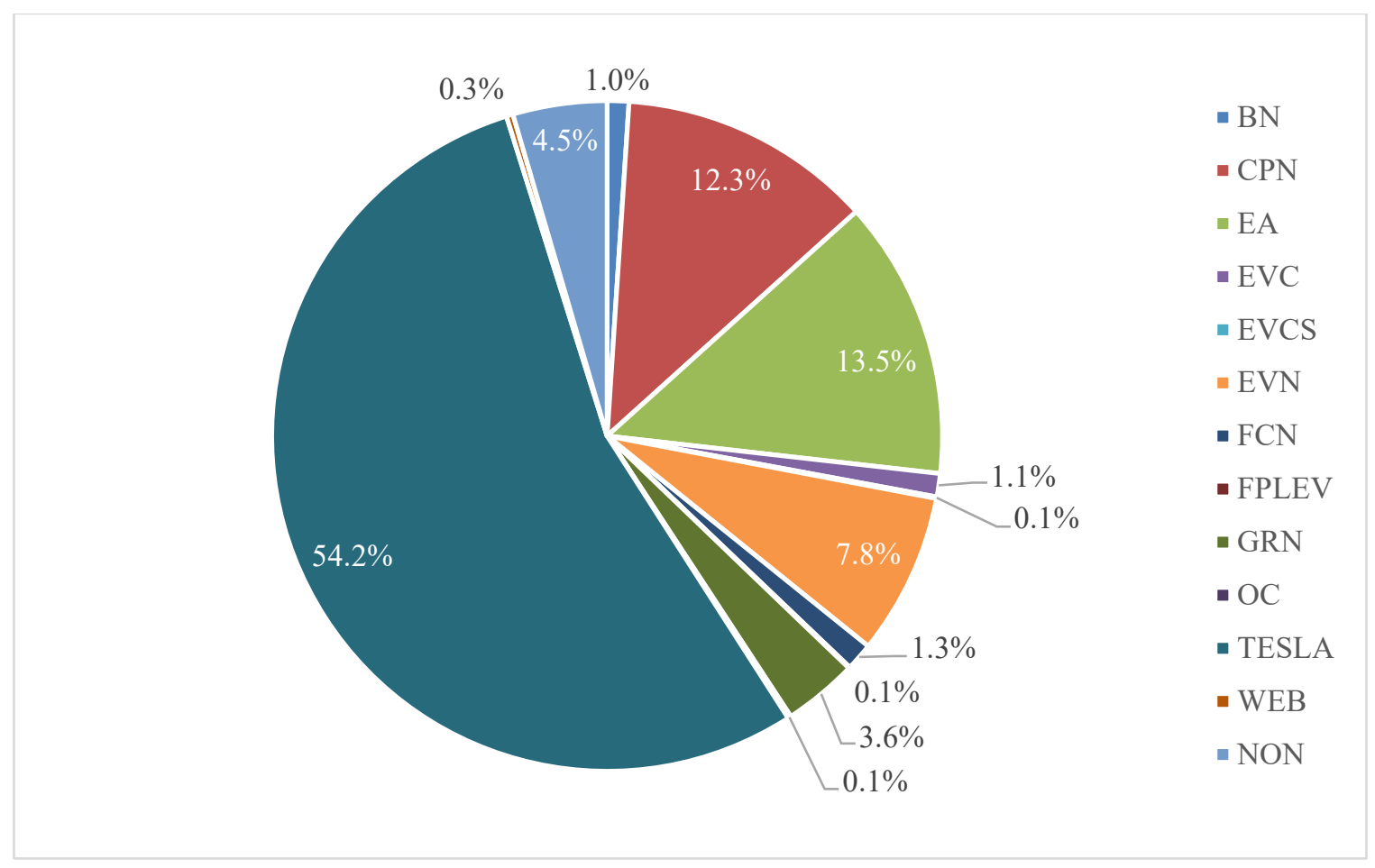

Figure 10. Breakdown of public DC fast EVSE by network in Q4 ${ }^{1}$

${ }^{1}$ Figure 10 excludes networks that have less than 10 public DC fast EVSE. 
Figure 11 shows the growth of each network in Q4, and Table 1 includes the percent growth of each network in Q4. The number of public EVSE on all networks grew in Q4 with the exceptions of the Francis, FPL EVolution, and Webasto networks, which did not change, and the EVgo and FLO networks, which decreased slightly (Table 1). The Francis and FPL EVolution networks did not have documented growth in Q4 because the Station Locator team did not receive updates from these networks. However, the Station Locator team received a large update from the Francis network in Q2, and the FPL EVolution was new to the Station Locator as of Q3. The team expects any stations added to these networks in Q4 to be reflected in future quarters. EVSE on the Webasto network are automatically uploaded to the Station Locator via an API, but the number of Webasto EVSE in the Station Locator has remained constant for over a year. The number of public EVSE on the EVgo and FLO networks only decreased by five and one EVSE, respectively.

Aside from the new networks, the number of EVSE on the PowerFlex network increased by the largest percentage in Q4, from two EVSE to 270 EVSE. PowerFlex was new to the Station Locator in Q3, and the Station Locator team worked with PowerFlex in Q4 to add all EVSE on the network. There was also a large increase on the Tesla Destination network $(27.5 \%)$ due to the update that the Station Locator team received from Tesla in Q4, as discussed in Section 1.1.2. Finally, Electrify America increased its public EVSE by $23.9 \%$, and a quarter of its new installations were in California. Of the $\$ 2$ billion that Electrify America plans to invest in charging infrastructure through 2026, \$800 million (40\%) will be invested in California (Electrify America 2021).

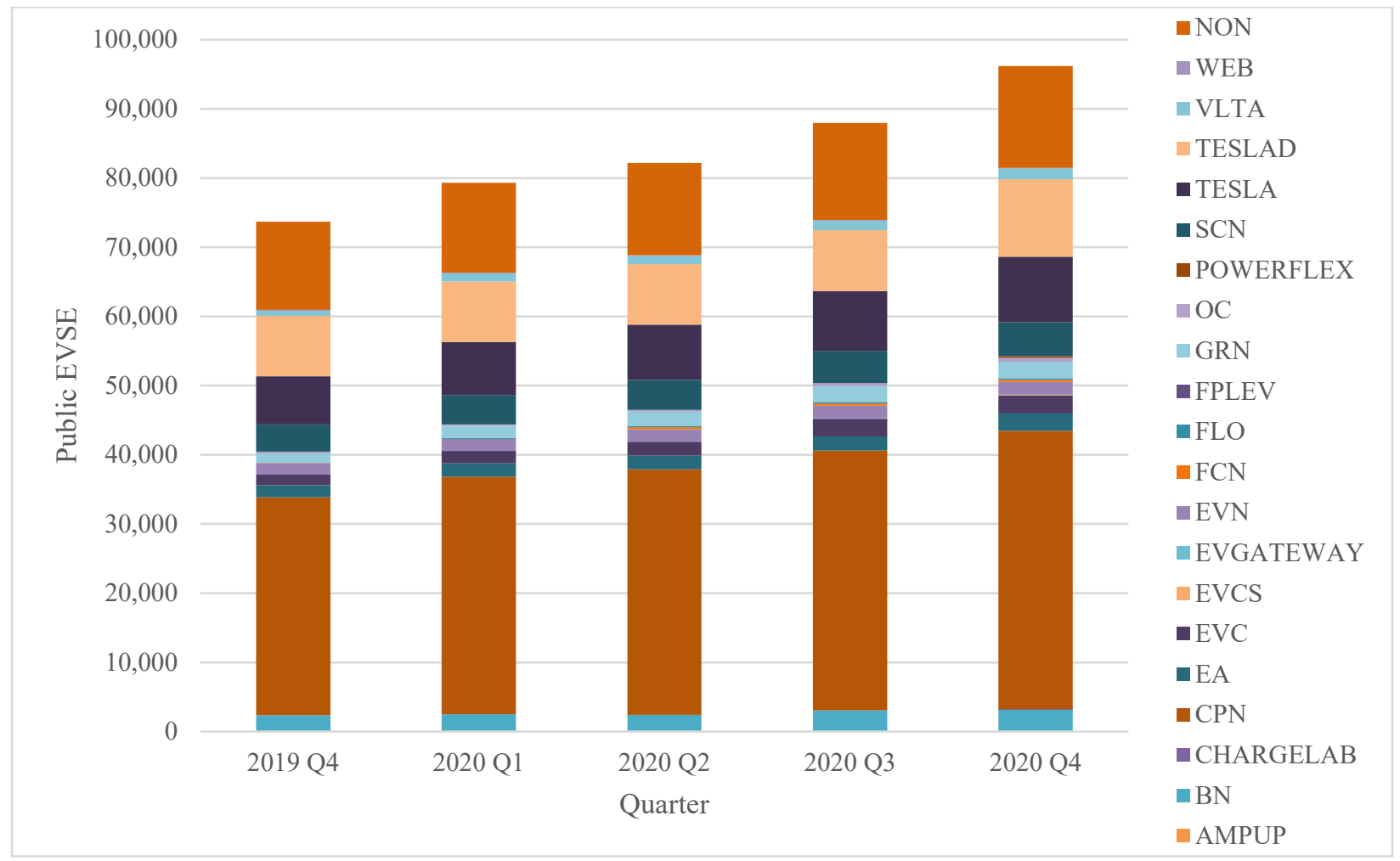

Figure 11. Quarterly growth of public EVSE by network 
Table 1. Quarterly Growth of Public EVSE by Network

\begin{tabular}{|c|c|c|c|c|}
\hline Network & Q1 Growth & Q2 Growth & Q3 Growth & Q4 Growth \\
\hline NON & $1.8 \%$ & $3.0 \%$ & $5.0 \%$ & $5.0 \%$ \\
\hline WEB & $0.9 \%$ & $-0.9 \%$ & $0.0 \%$ & $0.0 \%$ \\
\hline VLTA & $53.5 \%$ & $0.0 \%$ & $17.9 \%$ & $11.8 \%$ \\
\hline TESLAD & $0.2 \%$ & $0.0 \%$ & $0.2 \%$ & $27.5 \%$ \\
\hline TESLA & $10.1 \%$ & $4.3 \%$ & $8.8 \%$ & $9.0 \%$ \\
\hline $\mathrm{SCN}$ & $7.6 \%$ & $2.6 \%$ & $6.6 \%$ & $5.6 \%$ \\
\hline POWERFLEX & $\mathrm{N} / \mathrm{A}$ & $\mathrm{N} / \mathrm{A}$ & $\mathrm{N} / \mathrm{A}$ & $13,400.0 \%$ \\
\hline OC & $0.0 \%$ & $4.9 \%$ & $87.2 \%$ & $13.7 \%$ \\
\hline GRN & $24.2 \%$ & $18.9 \%$ & $13.0 \%$ & $5.0 \%$ \\
\hline FPLEV & $\mathrm{N} / \mathrm{A}$ & $N / A$ & N/A & $0.0 \%$ \\
\hline FLO & N/A & $25.8 \%$ & $3.7 \%$ & $-0.5 \%$ \\
\hline $\mathrm{FCN}$ & $0.0 \%$ & $31,100.0 \%$ & $0.0 \%$ & $0.0 \%$ \\
\hline EVN & $3.2 \%$ & $2.2 \%$ & $1.2 \%$ & $-0.3 \%$ \\
\hline EVGATEWAY & $\mathrm{N} / \mathrm{A}$ & $\mathrm{N} / \mathrm{A}$ & $\mathrm{N} / \mathrm{A}$ & $2.9 \%$ \\
\hline EVC & $17.7 \%$ & $11.2 \%$ & $29.8 \%$ & $3.2 \%$ \\
\hline EA & $11.9 \%$ & $2.3 \%$ & $1.2 \%$ & $23.9 \%$ \\
\hline CPN & $9.0 \%$ & $3.4 \%$ & $5.7 \%$ & $7.1 \%$ \\
\hline $\mathrm{BN}$ & $5.5 \%$ & $-3.4 \%$ & $27.3 \%$ & $3.5 \%$ \\
\hline Total & $7.6 \%$ & $3.3 \%$ & $7.0 \%$ & $9.2 \%$ \\
\hline
\end{tabular}

\subsubsection{By Region}

The Clean Cities Coalition Network is broken down into seven regions (Figure 12), which were used to analyze the growth of public EV charging infrastructure across the country (Clean Cities Coalition Network 2020a, 2020b). See the first report in this series for more information about the Clean Cities Coalition Network (Brown et al. 2020a). 


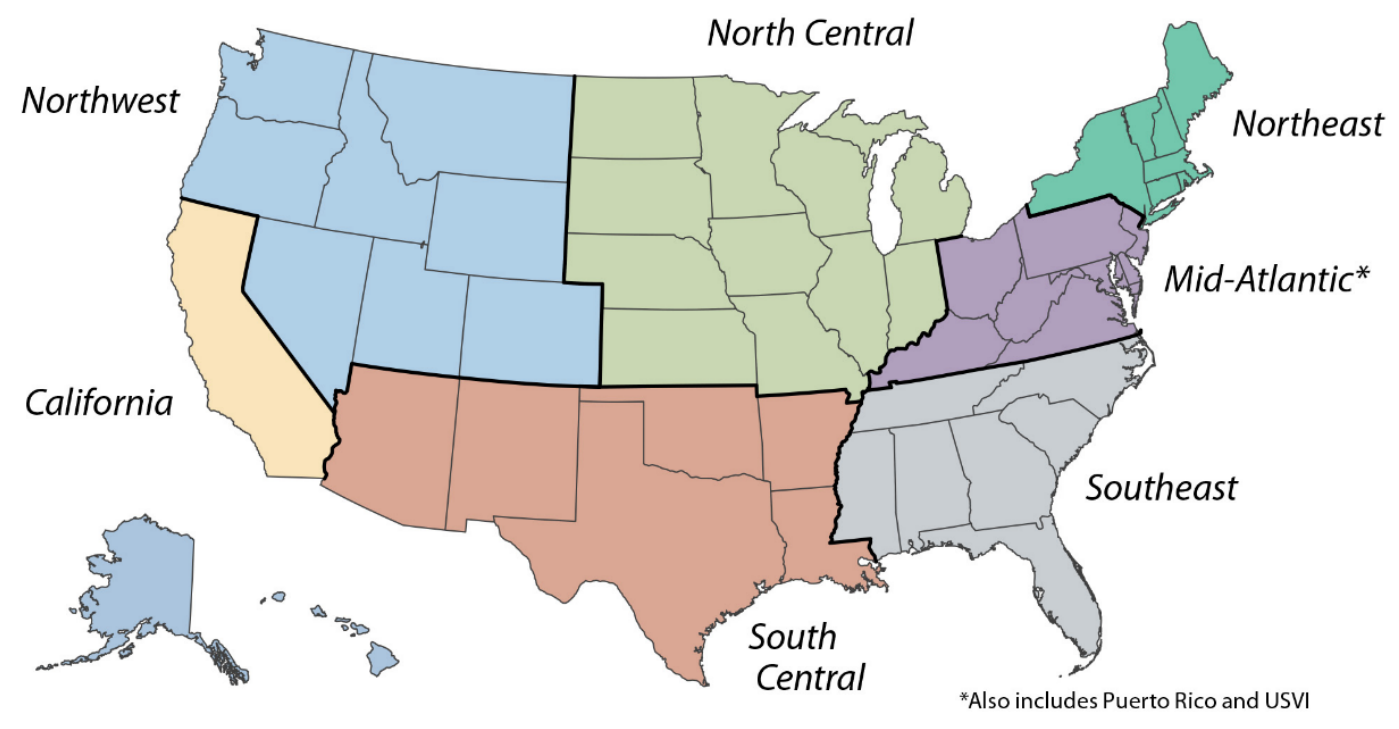

Figure 12. Clean Cities regions

As shown in Figure 13, the California region had both the largest share of the country's public EVSE (31.8\%) and grew by the largest percentage (10.2\%) in Q4. The North Central region grew by the smallest percentage (7.6\%) (Figure 13$)$.

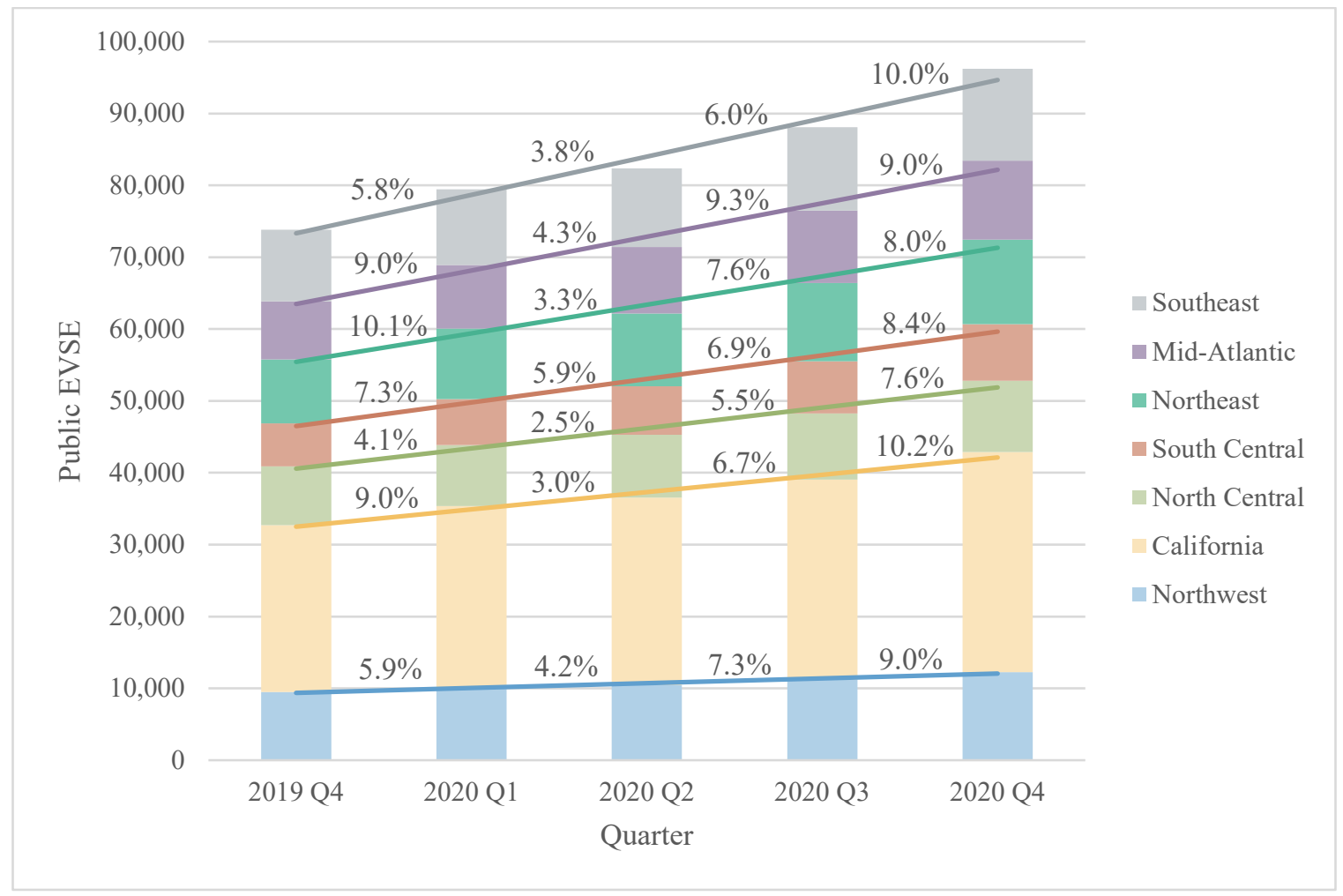

Figure 13. Quarterly growth of public EVSE by Clean Cities region 


\subsubsection{By State}

To track the growth of EVSE by state, the Station Locator team calculated the number of public EVSE per 100,000 people in each state. The team chose this metric to compare charging infrastructure development across states on a basis that accounts for proportional impact. Washington, D.C., is considered a state for the purpose of this analysis, and the population data used are based on the U.S. Census Bureau's 2020 estimates (U.S. Census Bureau 2020).

As of the end of Q4, the number of EVSE per 100,000 people ranged from 7.0 in Louisiana to 123.2 in Vermont. The five states with the highest number of EVSE per 100,000 people continue to be Vermont, Washington, D.C., California, Hawaii, and Colorado (Table 2). However, the five states that had the largest growth of EVSE per 100,000 people were Alaska, New Mexico, Nevada, South Carolina, and Washington, D.C. Note that although Alaska is currently among the bottom five states with the smallest number of EVSE per 100,000 people, the number of EVSE in Alaska grew by the largest percentage in Q4, which reflects the addition of $27 \mathrm{EVSE}$. The majority of the EVSE added are non-networked Level 2 EVSE. The growth in New Mexico is attributable to the ChargePoint network, and the growth in Nevada, South Carolina, and Washington, D.C., is largely attributable to the Tesla Destination network.

Table 2. States with the Highest Rate of EVSE per 100,000 People

\begin{tabular}{|c|c|}
\hline State & EVSE per 100,000 People \\
\hline Vermont & 123.2 \\
\hline Washington, D.C. & 84.5 \\
\hline California & 77.8 \\
\hline Hawaii & 50.2 \\
\hline Colorado & 49.5 \\
\hline
\end{tabular}

Table 3. States with the Largest Growth of EVSE per 100,000 People

\begin{tabular}{|c|c|}
\hline State & $\begin{array}{c}\text { Q4 Growth of EVSE per } \\
\mathbf{1 0 0 , 0 0 0} \text { People }\end{array}$ \\
\hline Alaska & $65.9 \%$ \\
\hline New Mexico & $21.1 \%$ \\
\hline Nevada & $18.7 \%$ \\
\hline South Carolina & $13.7 \%$ \\
\hline Washington, D.C. & $13.5 \%$ \\
\hline
\end{tabular}

\subsection{Private Charging Trends}

Private EV charging refers to EV charging stations that are available only to certain drivers for specific purposes, such as charging for transit fleets or employee-only charging at workplaces. Although the Station Locator team proactively seeks out new station openings to include, the opening of private workplace chargers may not necessarily be shared publicly. The Station Locator team therefore relies on Clean Cities coalitions, industry partners, and Station Locator 
users to share this information. Due to the challenge in collecting these data, the number of private, nonresidential charging stations in the Station Locator is likely underrepresented; however, the Station Locator team is continually working to improve the data collection in these areas.

In Q4, the number of private EVSE in the Station Locator decreased by 138, bringing the total number to 14,765 and representing a $0.9 \%$ decrease since Q3. The following sections break down the growth of private EVSE by level, as well as by two specific types: workplace charging and MUD charging.

\subsubsection{By Charging Level}

As shown in Figure 14, the majority of private EVSE in the Station Locator are Level 2.

However, DC fast EVSE grew by the largest percentage overall (2.6\%) in Q4 (Figure 14). The private DC fast EVSE in the Station Locator are predominately for government fleets, including a few public transit authorities, followed by car dealerships and workplace charging.

The decrease in private Level 2 EVSE is primarily attributable to the removal of out of service and duplicate General Electric (GE) WattStations from the Station Locator in Q4. ChargePoint took over GE's network in 2017, and as a result some GE WattStations are now on ChargePoint's network and imported automatically into the Station Locator. The decrease is also attributable to the removal of non-networked EVSE in California, Colorado, Massachusetts, and Ohio that the Station Locator team was unable to reach after several attempts. As discussed in Section 1.1.2, stations the Station Locator team is unable to contact are removed from the database as part of the annual unreachable station cleanup process.

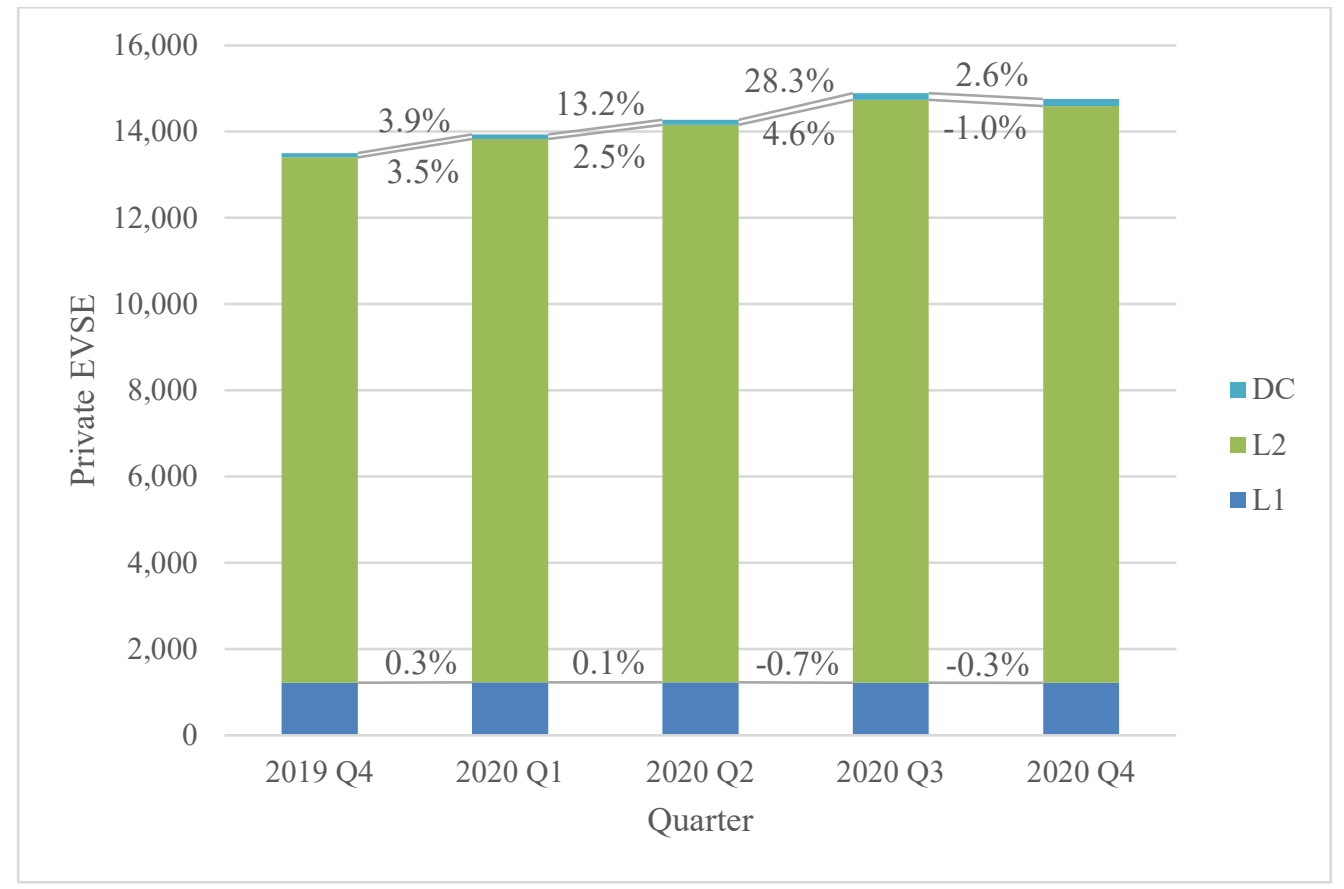

Figure 14. Quarterly growth of private EVSE by charging level 


\subsubsection{Workplace Charging}

Workplace EV charging infrastructure includes charging stations that are private or otherwise designated for employee use. The majority of private workplace EVSE in the Station Locator are Level 2 (Figure 15). This is to be expected because workplace chargers are used by employees while they are parked at work for an extended period and therefore do not necessarily need rapid charging.

As of the end of Q4, there were 8,930 workplace EVSE in the Station Locator. As shown in Figure 15, the number of DC fast EVSE grew by the greatest percentage $(7.7 \%)$ at workplaces in Q4, though this only represents an increase of three EVSE. The number of Level 2 workplace EVSE grew by 57 EVSE.

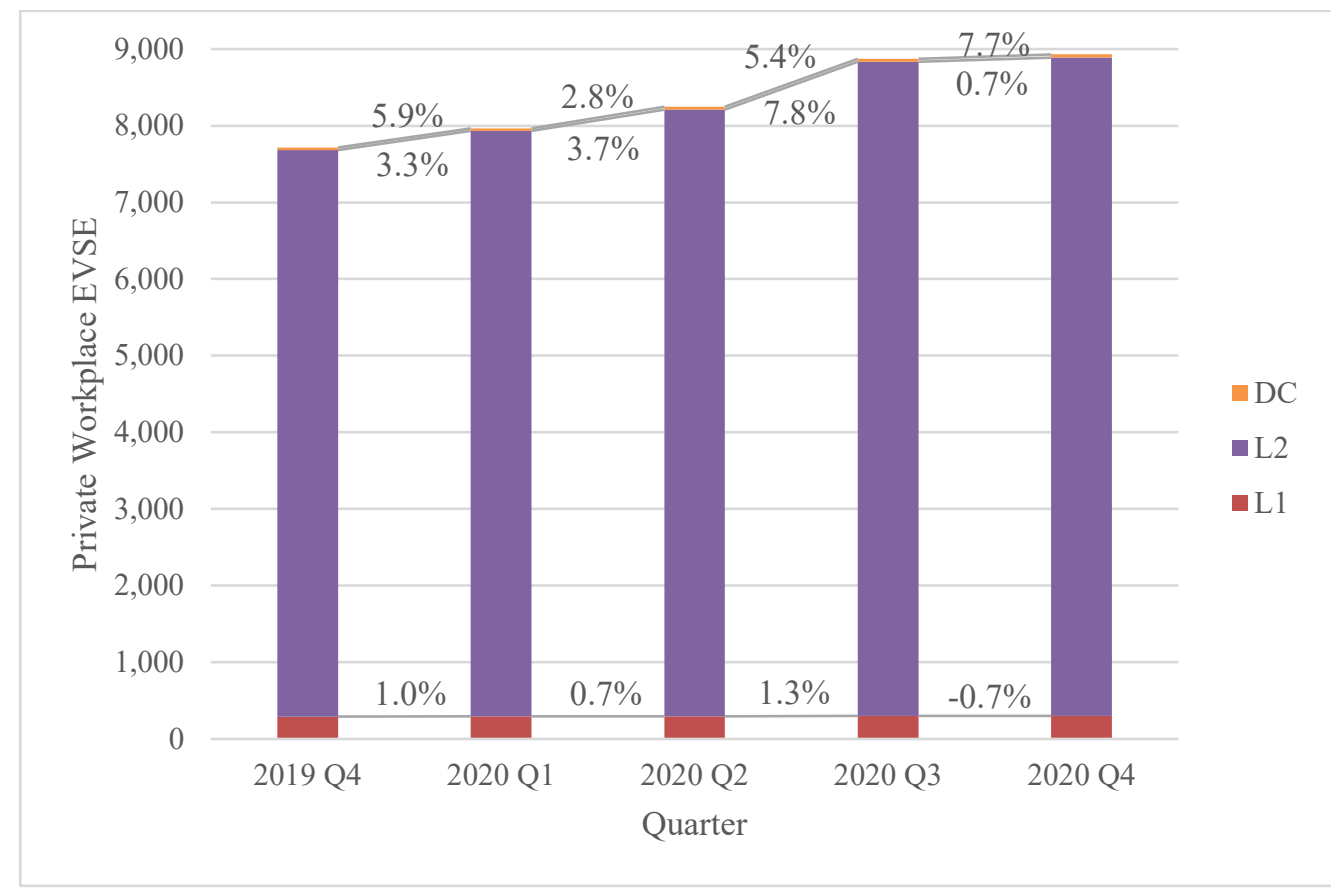

Figure 15. Quarterly growth of private workplace EVSE by charging level

\subsubsection{Multi-Unit Dwelling Charging}

In 2019, the Station Locator team began a focused effort to capture private charging infrastructure installed at MUDs that is available for resident use only. In Q4, there was a 22.7\% increase in MUD EVSE, bringing the total number of private MUD EVSE to 562 (Figure 16). MUD EVSE in the Station Locator are either Level 1 or Level 2, but, as with previous quarters, only Level 2 EVSE grew in Q4 (Figure 16). The large increase in Level 2 EVSE is attributable to the Q4 update that the Station Locator received from EV Connect, which contained many MUD EVSE.

The Station Locator team continues its concerted MUD data collection efforts, and the number of MUD EVSE is likely to continue to grow in future quarters. 


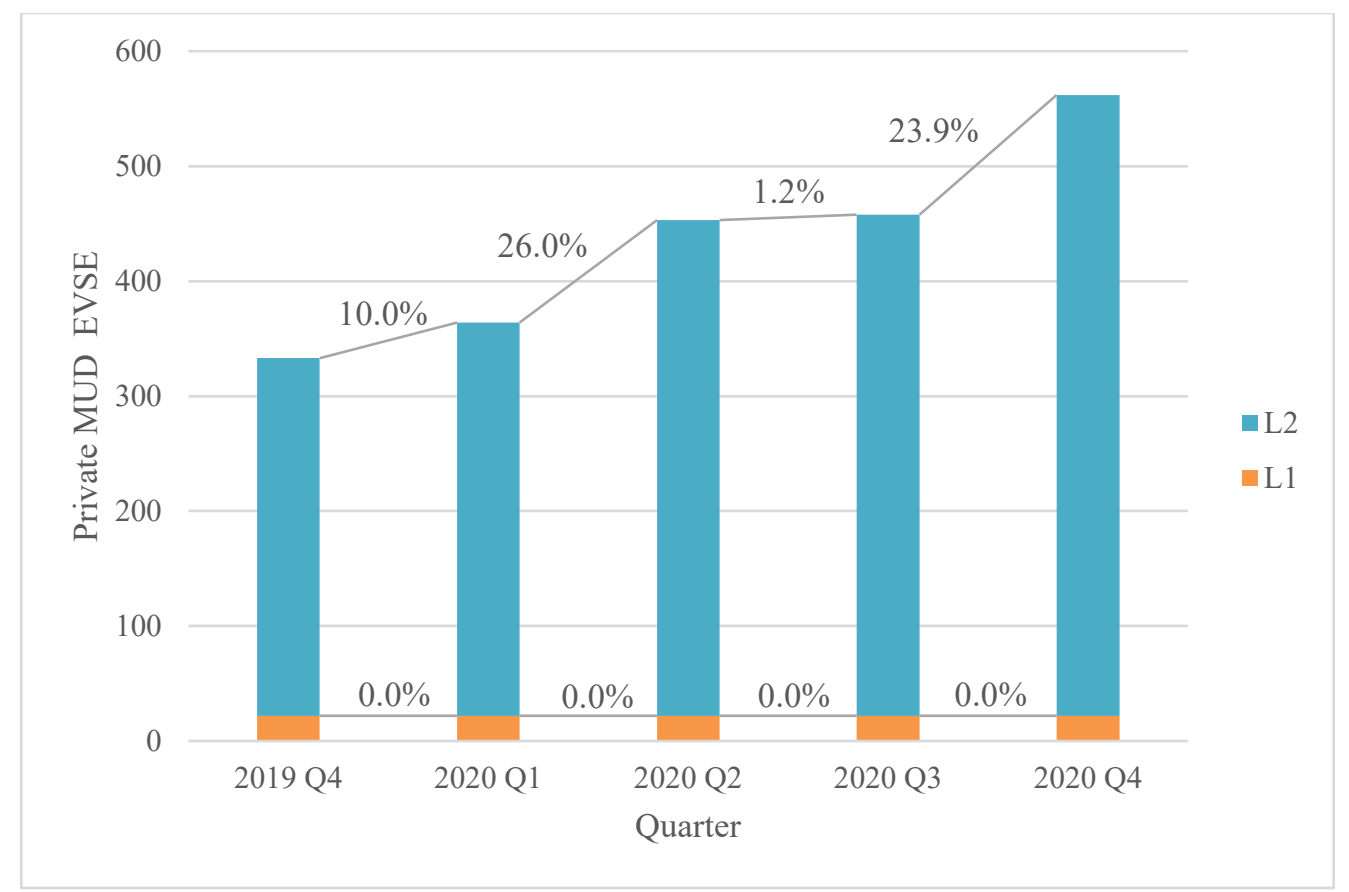

Figure 16. Quarterly growth of private MUD EVSE by charging level

\subsubsection{Fleet Charging}

In 2021, the Station Locator team will continue focusing on expanding its private fleet data collection efforts, especially for fleets that are installing charging infrastructure for medium- and heavy-duty vehicles such as school bus fleets and public transit fleets. Once a more robust data set is available, future quarterly reports will include data on the growth of this kind of charging infrastructure.

\section{Projecting Future Charging Infrastructure Needs}

NREL's 2017 National Plug-In Electric Vehicle Infrastructure Analysis estimated how much public and workplace EV charging infrastructure would be required in the United States to support a growing fleet of light-duty plug-in electric vehicles (PEVs), including both plug-in hybrid electric vehicles and all-electric vehicles (Wood et al. 2017). Based on the central scenario with 15 million light-duty PEVs on the road in 2030, this analysis estimated a total of 27,500 DC fast EVSE and 601,000 Level 2 EVSE would need to be available across the United States to meet charging needs. ${ }^{2}$ This equates to 1.8 DC fast EVSE per 1,000 PEVs and 40.1 Level 2 EVSE per 1,000 PEVs by 2030.

As of Q4, there were 17,472 public and workplace DC fast EVSE and 85,894 public and workplace Level 2 EVSE available in the United States (Figure 17). Based on NREL's 2017 analysis, the amount of DC fast and Level 2 EVSE installed is $63.5 \%$ and $14.3 \%$, respectively, of

\footnotetext{
${ }^{2}$ This analysis may underrepresent the trajectory of the industry given that it was completed in 2017. Since then, some states have established more ambitious electrification plans and the federal government has made significant electrification commitments (see Section 4). Future reports will address this.
} 
the way toward meeting projected 2030 infrastructure requirements (Figure 17). As with previous quarters, it is important to note that $54.2 \%$ of public DC fast EVSE in the Station Locator are on the Tesla Supercharger network and therefore only readily accessible to Tesla drivers. Additionally, as of the end of December 2020, approximately $44 \%$ of PEVs on the road were Teslas (IHS Markit 2018; Zhou 2020). ${ }^{3}$ When public Tesla EVSE are excluded, the amount of DC fast and Level 2 EVSE currently installed is $29.2 \%$ and $12.4 \%$, respectively, of the way toward meeting projected 2030 infrastructure requirements.

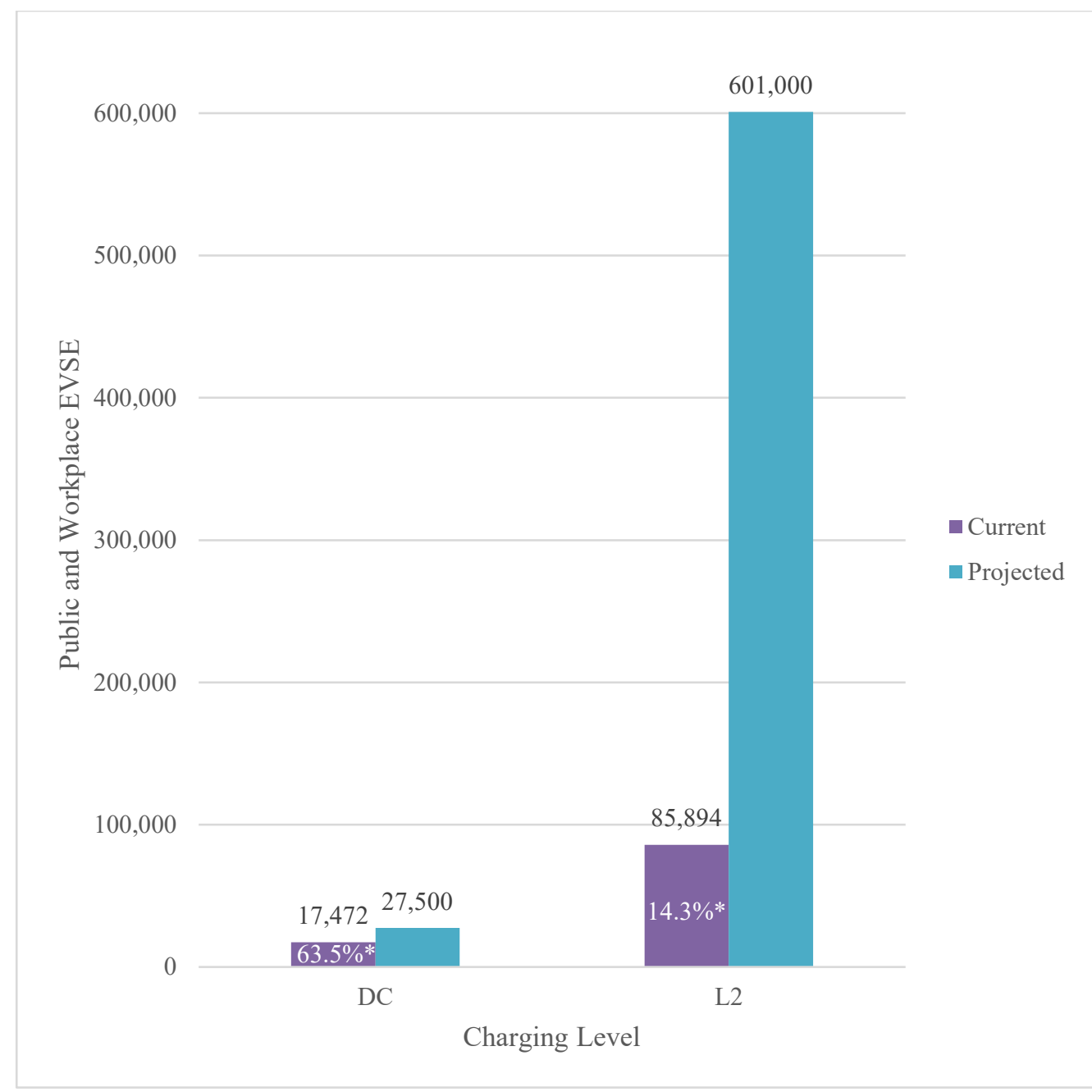

Figure 17. Current availability and projected 2030 need of public and workplace charging in the United States

*Indicates the percent of projected EVSE that have been installed as of Q4.

${ }^{3}$ This percentage is based on the number of cumulative Tesla sales in the United States from 2011 through December 2020, 2018 PEV registration data, and 2019 and 2020 light-duty PEV sales data. This figure does not account for Teslas that have been retired since 2011 or total light-duty PEVs that were retired in 2019 and 2020. 
As of Q4, there were approximately 1.6 million PEVs in the United States' light-duty fleet (IHS Markit 2018; Zhou 2020). ${ }^{4}$ The ratio of DC fast and Level 2 public and workplace EVSE per 1,000 PEVs in Q4 was 10.7 and 52.5, respectively (Figure 18). This ratio decreases to 4.9 and 45.6 when Tesla EVSE are excluded. Using NREL's 2017 analysis' estimated ratio of 1.8 DC fast and 40.1 Level 2 EVSE per 1,000 PEVs as a proxy for how much infrastructure is sufficient to meet charging needs, Figure 18 indicates that, as of Q4, there was enough public and workplace DC fast and Level 2 EVSE in the United States as a whole to meet projected charging needs. However, this comparison does not speak to whether the geographic distribution of EVSE matches where there is charging demand. Future reports will include more granular data on the geographic distribution of EVSE across the United States. Additionally, it is notable that only $10.9 \%$ of the 15 million light-duty PEVs projected for 2030 were on the road as of Q4 (Zhou 2020). Light-duty PEV sales hit a record high in 2018, declined in 2019, and suffered in the first half of 2020 due to the coronavirus pandemic (Zhou 2020). However, the U.S. PEV market began making a comeback in Q3, and as discussed in the next section, closed out 2020 with the second-highest PEV sales record in U.S. history, indicating that PEV sales will continue to increase.

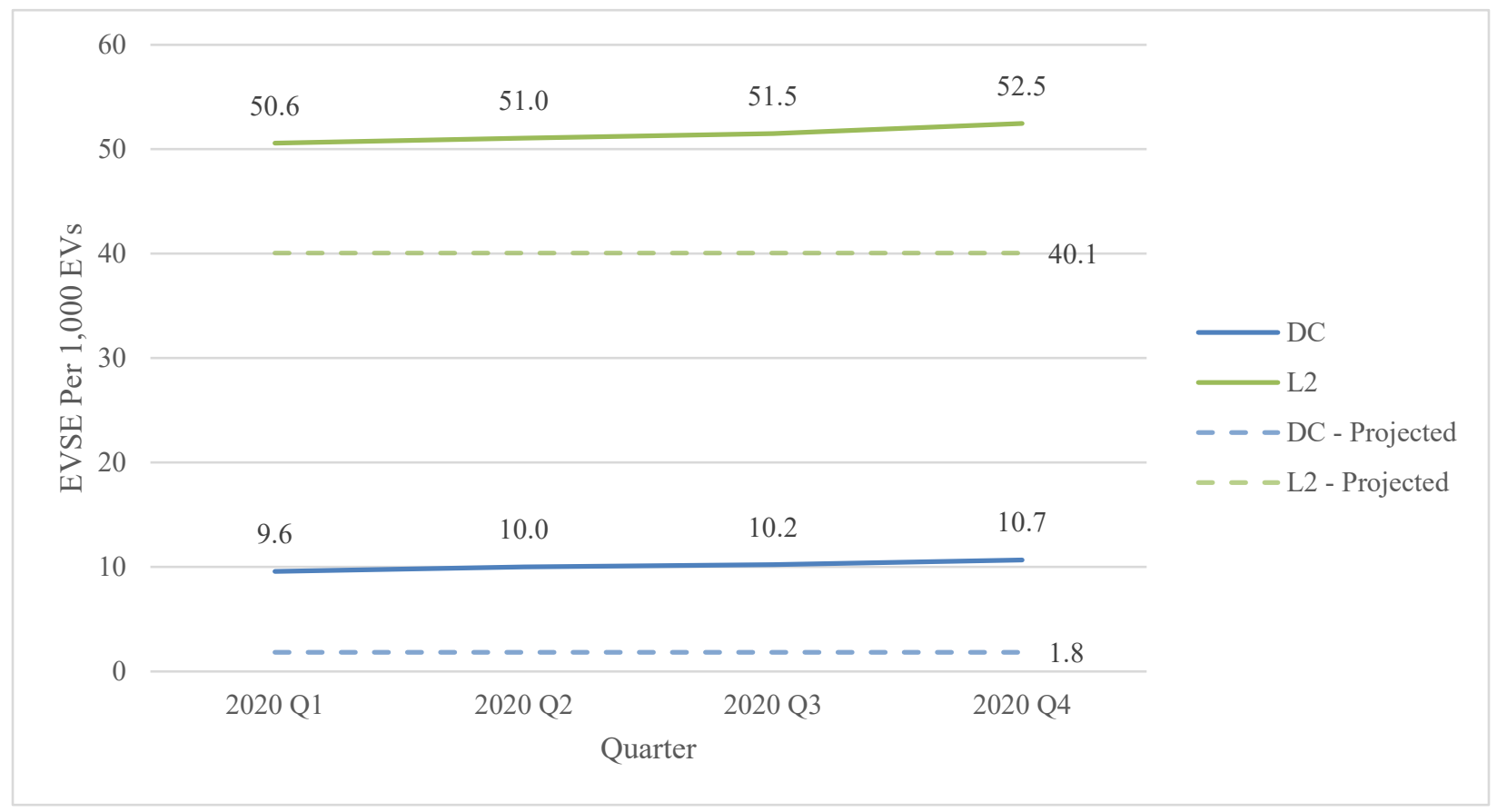

Figure 18. Quarterly availability and projected 2030 need of public and workplace EVSE per 1,000 EVs in the United States

${ }^{4}$ U.S. 2019 and 2020 PEV registration data are not yet available. The number of PEVs as of December 2020 is based on 2018 PEV registration data and 2019 and 2020 light-duty PEV sales data. Therefore, the 1.6 million figure does not account for vehicles that were retired in 2019 and 2020 and may overestimate the number of PEVs on the road. 


\section{Developments That Could Impact Future Quarters}

The election of Joseph R. Biden Jr. as the $46^{\text {th }}$ president of the United States is perhaps the single Q4 development that could have the largest impact on future EV infrastructure growth. Biden has pledged to make significant investments in the U.S. EV market, including installing 500,000 charging stations across the country (Biden for President 2021). Future reports will include updates on these investments as pledges turn into plans and plans turn into action.

Furthermore, the Zero Emission Transportation Association (ZETA), an industry-backed advocacy organization comprised of $28 \mathrm{EV}$ charging networks and equipment manufacturers, EV manufacturers, utilities, and mineral producers across the United States, launched shortly after Biden's election (Zero Emission Transportation Association 2020). ZETA's mission is to enable $100 \%$ of new light-, medium-, and heavy-duty vehicle sales in the United States to be electric by 2030. One of ZETA's policy pillars to achieve this goal is a national charging initiative, including a federal investment of $\$ 30$ billion to build out public charging infrastructure and prioritizing infrastructure development along the National Highway Freight Network (Zero Emission Transportation Association n.d.). While the founding members of ZETA do not include the United States' largest vehicle manufacturers - General Motors, Ford, and Fiat ChryslerZETA's members include several influential stakeholders in the EV space that will be important for the Biden administration to engage with to implement its infrastructure plans.

Q4 also saw existing charging networks expand their business models and new charging networks arise. Electrify America turned its sights toward the business-to-business sector with the launch of its new Electrify Commercial business unit (Mercure 2020). Electrify Commercial will help utilities, fleet owners and operators, government entities, and businesses design, implement, and manage their own customized charging programs. Rivian, the all-electric pick-up truck and sport utility vehicle manufacturer, will begin building out its own charging network called the Rivian Adventure Network (Korosec 2020). Rivian plans to install over 3,500 DC fast chargers along highways and main roads by the end of 2023 that are available to Rivian customers only, similar to the Tesla model (Rivian 2021). However, Rivian will also install public Level 2 chargers that are available to any EV driver and will have over 10,000 chargers planned by the end of 2023, with installations beginning at its first locations in July 2021 (Rivian 2021). The Station Locator team is working with Rivian to add these stations to the database.

The U.S. EV market continued to rebound from pandemic-related setbacks earlier in the year and finished 2020 strong, with total PEV sales up 40.3\% in December 2020 compared with December 2019 (Zhou 2020). There were 41,836 PEVs sold in December 2020, making it the second-highest month for PEV sales in U.S. history (Zhou 2020; Atlas Public Policy 2021). As a result of this increase in sales, total PEV sales for 2020 only decreased by $3 \%$ compared with total 2019 sales (Atlas Public Policy 2021). EV sales are likely to continue to increase as major vehicle manufacturers were busy doubling down on their electrification investments and commitments in Q4. Ford announced an additional \$3.2 billion in new investments for its forthcoming all-electric vehicles, including the all-electric Transit van and F-150 (Wayland 2020). GM increased its original investment of $\$ 20$ billion through 2025 to $\$ 27$ billion and plans to have 30 all-electric models available by 2025 (GM 2020). Similarly, Hyundai plans to have 23 all-electric models available by 2025, and Volkswagen plans to have 70 all-electric models available by 2030 (Hyundai 2020; Volkswagen 2020). By the end of 2021, 60\% of Fiat 
Chrysler's Fiat models will be PEVs (Reuters Staff 2020a). Finally, luxury car brands Maserati and Bentley announced that they will only offer PEVs by 2025 and 2026, respectively (Bentley 2020; Reuters Staff 2020b).

Finally, the Station Locator data collection and management processes will continue to impact future EVSE counts as well. As noted in Section 1.1.1, since 2019, the Station Locator team has been transitioning its counting logic to align with the hierarchy defined in the OCPI protocol: locations, EVSE, and connectors (EVRoaming Foundation 2019). With this transition, the Station Locator is now counting the number of EVSE at a station location rather than the number of connectors previously counted. For example, a charging location with one EVSE and two connectors was previously counted twice but is now only counted once using the OCPI protocol's counting logic. As of Q4, all manually collected data, as well as EVSE on the Electrify America and EVgo networks, are counted according to the OCPI logic. The integration of ChargePoint's and Greenlots' OCPI APIs into the Station Locator was completed in the first quarter of 2021. Additionally, as discussed in Section 1.1.1, NREL is continuously working with EVSPs to add new APIs to the Station Locator. As these new APIs come online, there will likely be an increase in the number of EVSE in the Station Locator.

\section{Conclusion}

This paper examines the growth of EV infrastructure in the Station Locator, including the growth of public EV charging by charging level, network, region, and state, and the growth of private EV charging by charging level and use type (i.e., workplace and MUD), in Q4 of 2020. With such rapid growth and change in EV charging infrastructure, the information presented in this paper aims to help readers understand how and where the infrastructure is developing, where there may be areas of opportunity, and whether development is keeping pace with projected charging demand.

As of the end of Q4, Level 2 chargers accounted for the majority of both public and private EVSE in the Station Locator (80.4\% and $90.7 \%$, respectively), though public and private DC fast EVSE grew by the largest percentage (10.8\% and $2.6 \%$, respectively). California continues to lead the country in terms of the total number of public EVSE available $(30,635)$, but drops in rank to third when compared to other states based on EVSE available per 100,000 people. California also led the country in terms of percent growth in Q4 (10.2\%), whereas the number of EVSE in the North Central region grew by the smallest percentage in Q4 (7.6\%).

Based on NREL's 2017 projection of the number of public and workplace Level 2 chargers required to meet charging demand in 2030, the number of DC fast and Level 2 EVSE is 63.5\% and $14.3 \%$, respectively, of the way toward meeting projected 2030 needs (Wood et al. 2017). The number of DC fast EVSE and Level 2 EVSE per 1,000 PEVs was 10.7 and 52.5, respectively, compared with NREL's projected need of 1.8 and 40.1, respectively. Using NREL's ratios as a proxy for current charging needs, this indicates that infrastructure development is keeping up with, and even surpassing, projected charging needs in terms of the total amount available across the United States. It is important to note, however, that the majority $(54.2 \%)$ of public DC fast EVSE in the Station Locator are on the Tesla network and are therefore only readily accessible to Tesla drivers. 
Finally, as the Station Locator team adds new charging networks to the Station Locator and continues its concerted effort to collect MUD and fleet charging data, there will continue to be large increases in the number of EVSE available.

If there are additional metrics that readers are interested in seeing, please email suggestions to the authors at TechnicalResponse@,icf.com. 


\section{References}

Alternative Fuels Data Center. 2020a. "About the Alternative Fuels Data Center." Accessed April 15, 2021. https://afdc.energy.gov/about.html.

Alternative Fuels Data Center. 2020b. "Alternative Fueling Station Locator.” Accessed April 15, 2021. https://afdc.energy.gov/stations/\#/find/nearest.

Alternative Fuels Data Center. 2020c. "Data Included in the Alternative Fueling Station Data." Accessed April 15, 2021. https://afdc.energy.gov/data_download/alt_fuel_stations_format.

Atlas Public Policy. 2021. "Year-Over-Year EV Sales Up 43 Percent in January.” EV Hub Weekly Digest, March 22, 2021.

Bentley. 2020. "Bentley and Electrification: The Journey Starts Here." Accessed April 15, 2021. https://www.bentleymotors.com/en/world-of-bentley/the-bentley-story/future/bentley-andelectrification-the-journey-starts-here.html.

Biden for President. 2021. "The Biden Plan to Build a Modern, Sustainable Infrastructure and an Equitable Clean Energy Future.” Accessed April 14, 2021. https://joebiden.com/clean-energy/.

Brown, Abby, Stephen Lommele, Alexis Schayowitz, and Emily Klotz. 2020a. Electric Vehicle Charging Infrastructure Trends from the Alternative Fueling Station Locator: First Quarter 2020. Golden, CO: National Renewable Energy Laboratory. NREL/TP-5400-77508. www.nrel.gov/docs/fy20osti/77508.pdf.

Brown, Abby, Stephen Lommele, Alexis Schayowitz, and Emily Klotz. 2020b. Electric Vehicle Charging Infrastructure Trends from the Alternative Fueling Station Locator: Second Quarter 2020. Golden, CO: National Renewable Energy Laboratory. NREL/TP-5400-78486. https://www.nrel.gov/docs/fy21osti/78486.pdf.

Brown, Abby, Stephen Lommele, Alexis Schayowitz, and Emily Klotz. 2021. Electric Vehicle Charging Infrastructure Trends from the Alternative Fueling Station Locator: Third Quarter 2020. Golden, CO: National Renewable Energy Laboratory. NREL/TP-5400-79536. https://www.nrel.gov/docs/fy21osti/79536.pdf.

Clean Cities Coalition Network. 2020a. “About Clean Cities.” Accessed April 15, 2021. https://cleancities.energy.gov/about/.

Clean Cities Coalition Network. 2020b. "Technology Integration Program Contacts." Accessed April 15, 2021. https://cleancities.energy.gov/contacts/?open=regional\#headingregionalManagers.

Electrify America. 2021. “Our Investment Plan.” Accessed April 15, 2021. https://www.electrifyamerica.com/our-plan/.

EVRoaming Foundation. 2019. OCPI 2.2: Open Charge Point Interface. Document Version 2.2, September 30, 2019. https://evroaming.org/app/uploads/2020/06/OCPI-2.2-d2.pdf. 
GM. 2020. "GM Boosts Investment, Grows Electric Portfolio in EV Race." GM Corporate Newsroom, November 19, 2020.

https://plants.gm.com/media/us/en/gm/news.detail.html/content/Pages/news/us/en/2020/nov/111 9-electric-portfolio.html.

Hyundai. 2020. "Hyundai to lead charge into electric era with EV platform 'E-GMP'." Hyundai Newsroom, December 2, 2020. https://www.hyundai.news/eu/articles/press-releases/hyundai-tolead-charge-into-electric-era-with-ev-platform-e-gmp.html.

IHS Markit. 2018. Derived Vehicle Registration Data by Fuel Type for the U.S. Golden, Colorado: National Renewable Energy Laboratory.

Korosec, Kirsten. 2020. "Rivian is building its own EV charging network, but with an adventurous twist." TechCrunch, December 8, 2020. https://techcrunch.com/2020/12/08/rivianis-building-its-own-ev-charging-network-but-with-an-adventurous-twist/?guccounter=2.

Levene, Johanna, Stephen Lommele, Robert Eger, and Wendy Dafoe. 2019. "Developing a Comprehensive Database of Alternative Fuel Station Locations across Canada and the United States of America." In Canadian Transportation Research Forum 54 ${ }^{\text {th }}$ Annual Conference Proceedings, 2019.

Mercure, Matthew. 2020. "Electrify America Launches Electrify Commercial Business Unit." NGTNews, October 28, 2020. https://ngtnews.com/electrify-america-launches-electrifycommercial-business-unit.

Reuters Staff. 2020a. "Fiat brand to electrify $60 \%$ of its models by end-2021: Executive." Reuters, December 1, 2020. https://www.reuters.com/article/us-fiat-chrysler-fiatelectrification/fiat-brand-to-electrify-60-of-its-models-by-end-2021-executiveidUSKBN28B54F.

Reuters Staff. 2020b. "Maserati to electrify entire line-up in next five years - CEO." Reuters, November 26, 2020. https://www.reuters.com/article/us-fiat-chrysler-maserati/maserati-toelectrify-entire-line-up-in-next-five-years-ceo-idUSKBN286167.

Rivian. 2021. "Charging Your Rivian.” Accessed April 15, 2021. https://stories.rivian.com/charging-your-rivian.

U.S. Census Bureau. 2019. "NST-EST2019-01: Table 1. Annual Estimates of the Resident Population for the United States, Regions, States, and Puerto Rico: April 1, 2010 to July 1, 2019." Accessed June 5, 2020. https://www.census.gov/newsroom/press-kits/2019/national-stateestimates.html.

U.S. Census Bureau. 2020. "Annual Estimates of the Resident Population for the United States, Regions, States, and the District of Columbia: April 1, 2010 to July 1, 2020 (NST-EST2020)." Accessed February 23, 2021. https://www.census.gov/programs-surveys/popest/technicaldocumentation/research/evaluation-estimates.html. 
Volkswagen. 2020. "Volkswagen Group raises investments in future technologies to EUR 73 billion." Accessed April 15, 2021. https://www.volkswagen-newsroom.com/en/pressreleases/volkswagen-group-raises-investments-in-future-technologies-to-eur-73-billion-6607.

Wayland, Michael. 2020. "Ford to invest $\$ 100$ million in Missouri plant to produce all-electric van." $C N B C$, November 10, 2020. https://www.cnbc.com/2020/11/10/ford-to-invest-100million-in-missouri-plant-to-produce-all-electric-van.html.

Wood, Eric, Clément Rames, Matteo Muratori, Sesha Raghavan, and Marc Melaina. 2017. National Plug-In Electric Vehicle Infrastructure Analysis. Golden, CO: National Renewable Energy Laboratory. https://www.nrel.gov/docs/fy17osti/69031.pdf.

Zero Emission Transportation Association. 2020. "Clean Transportation Leaders Launch Zero Emission Transportation Association." Zero Emission Transportation Association, November 17, 2020. https://www.zeta2030.org/news/clean-transportation-leaders-launch-zero-emissiontransportation-association/.

Zero Emission Transportation Association. n.d. "Policy Platform." Accessed April 15, 2021. https://www.zeta2030.org/policy-platform/.

Zhou, Joann. 2020. Annual U.S. Plug-In Electric Vehicle Sales, 2020. Distributed by Argonne National Laboratory. 